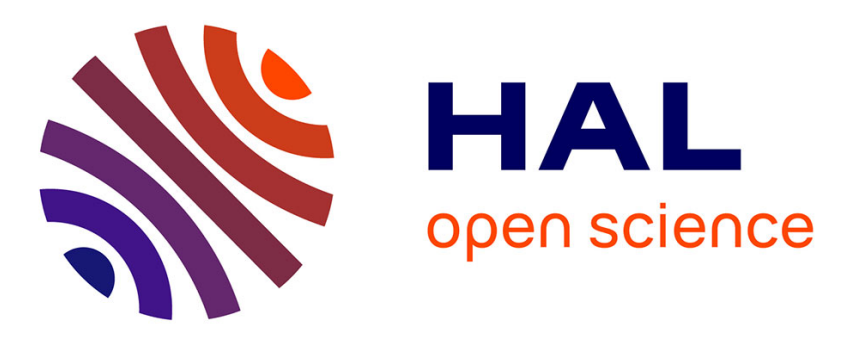

\title{
Biases and improvements in three dynamical downscaling climate simulations over China
}

Hao Yang, Zhihong Jiang, Laurent Li

\section{To cite this version:}

Hao Yang, Zhihong Jiang, Laurent Li. Biases and improvements in three dynamical downscaling climate simulations over China. Climate Dynamics, 2016, 47 (9), pp.3235-3251. 10.1007/s00382-0163023-9 . hal-01416309

\section{HAL Id: hal-01416309 \\ https://hal.sorbonne-universite.fr/hal-01416309}

Submitted on 14 Dec 2016

HAL is a multi-disciplinary open access archive for the deposit and dissemination of scientific research documents, whether they are published or not. The documents may come from teaching and research institutions in France or abroad, or from public or private research centers.
L'archive ouverte pluridisciplinaire HAL, est destinée au dépôt et à la diffusion de documents scientifiques de niveau recherche, publiés ou non, émanant des établissements d'enseignement et de recherche français ou étrangers, des laboratoires publics ou privés. 


\title{
Biases and Improvements in three Dynamical Downscaling Climate Simulations over China
}

(1)

Hao Yang ${ }^{1,2} \cdot$ Zhihong Jiang $^{1} \cdot$ Laurent $\mathrm{Li}^{3}$

\begin{abstract}
A dynamical downscaling is performed to improve the regional climate simulation in China. It consists of using a variable resolution model LMDZ4 nested into three global climate models (GCMs): BCC-csm1-1-m, FGOALS-g2 and IPSL-CM5A-MR, respectively. The regional climate from different simulations is assessed in terms of surface air temperature and rainfalls through a comparison to observations (both station data and gridded data). The comparison includes climatic trends during the last 40 years, statistical distribution of sub-regional climate, and the seasonal cycle. For surface air temperature, a significant part of the improvement provided by LMDZ4 is related to the effect of surface elevation which is more realistic in high-resolution simulations; the rest is related to changes in regional or local atmospheric general circulation. All GCMs and the downscaling model LMDZ4 are, more or less, able to describe the spatial distribution of surface air temperature and precipitation in China. LMDZ4 does show its superiority, compared to GCMs, in depicting a good regional terrain including the Tibetan Plateau, the Sichuan Basin and the Qilian Mountains.
\end{abstract}

Accepted manuscript for Climate Dynamics, Feb. 2016

1. Key Laboratory of Meteorological Disaster of Ministry of Education, Collaborative Innovation Center on Forecast and Evaluation of Meteorological Disasters, Nanjing University of Information Science and Technology, Nanjing, China

2. Hubei Key Laboratory for Heavy Rain Monitoring and Warning Research, Institute of Heavy Rain, China Meteorological Administration, Wuhan, China

3. Laboratoire de Météorologie Dynamique, CNRS/UPMC, Paris, France

Hao Yang, E-mail:yanghao0202@126.com

Corresponding Author: Zhihong Jiang, E-mail: zhjiang@ @uist.edu.cn

Laurent Li, E-mail: laurent.li@lmd.jussieu.fr 


\section{Introduction}

Numerical modeling is one of the most effective tools for climate change researches. There are more than 40 global models participating in the Coupled Model Intercomparison Project phase 5 (CMIP5) (Taylor et al. 2012) which provides a large number of climate simulations. Compared to the previous exercise CMIP3, the ability of simulating historical climate at global scale has been largely enhanced (Taylor et al. 2012; Sperber et al. 2012). However, the ability of simulating climate at regional scale is still poor, in particular for rainfall (Kitoh et al. 2013; Jiang et al. 2015).

China, located in the East Asian monsoon area, is one of the regions in the world possessing large climate variability. A complex surface topography also increases the difficulties for GCMs to accurately simulate the regional climate (Sperber et al. 2012). The main reason arises from their low spatial resolution, not capable of considering regional scale forcing, such as the complex terrain. The heterogeneity of surface conditions generally makes regional climate simulations unreliable. This is particularly true for the Tibetan Plateau and the surrounding areas (Mannig et al. 2013). To get higher-resolution and good-quality data, downscaling is indispensable (van Vuuren et al. 2011; Gao et al. 2010; Chen et al. 2011a; Jiang et al. 2012; Guo et al. 2012; Guo et al. 2014).

The technique of dynamical downscaling generally consists of using a high-resolution regional model nested into global models. It ensures a complete coherence among different variables. With a refined terrain, the capability of the regional model in simulating local weather and climate can be significantly improved (Giorgi et al. 2004; Frei et al. 2006). Based on this dynamical downscaling methodology, a few investigations on regional climate over China have been reported (Shi et al. 2011; Zhang 2012; Gao et al. 2012; Wang et al. 2013). However, there is still a lack of downscaling studies with multi-model global forcing, obviously due to the large demand on computer resources.

An alternative to the limited-area modeling is to generate regional climate information with variable-resolution (zoomed) global atmosphere general circulation models, the higher-resolution domain being put over the region of interest (Deque and Piedelievre 1995; Goubanova and Li 2007). Such a global model can also work as a traditional limited-area model if the whole globe outside the interested domain is considered as buffer zone which is driven by re-analysis data or 6-hourly outputs of global ocean-atmosphere coupled models. Such a regional configuration apparently wastes computer resources, the buffer zone where nudging takes place covering the 
whole globe. But this over-consumption is generally tolerable, since the number of model grids outside the interested domain is relatively limited if the zoom is appropriately designed. The advantage of this regional modelling approach resides in its general universality for different regions on Earth. LMDZ4, developed in the Laboratoire de Météorologie Dynamique, France, is a variable-grid GCM with the possibility of zooming and nudging. Many applications have been reported for different regions of the world: the Mediterranean (Li 2006, Rojas et al. 2013; L'Heveder et al. 2013; Vautard et al. 2013); South America (Carril et al. 2012; Solman et al. 2013). Regional applications were also reported over East Asia (Zou et al. 2010; Chen et al. 2011a).

As part of the Coordinated Regional Climate Downscaling Experiment (CORDEX) project (Giorgi et al. 2009), we simulate and analyze regional climate change signals over China under different scenarios. The particularity of our study is to use LMDZ-regional to conduct an ensemble of climate downscaling simulations with outputs of many global models (three when the paper was written). Simulations cover present day (1961-2005) and future (2006-2100) for RCP4.5 and RCP8.5 IPCC scenarios (Taylor et al. 2012). We hope that the multi-model ensemble approach allows us to deal with the issue of uncertainty by examining the spread of results.

In this paper, we describe results from LMDZ4 nested into three CMIP5 global simulations. Section 2 describes the model and data used. In section 3.1 to 3.3, the simulation performance between global models and their counterparts after downscaling is compared. Section 3.4 presents a simple off-line bias-correction method applied to surface air temperature, by revising the surface elevation in global models and LMDZ4. We believe that this correction, directly related to surface terrain, is meaningful for impact studies that might need high quality in surface air temperatures. Since there is no simple methodology allowing a bias correction for precipitations, the added value of regional simulations is much clearer for precipitations.

\section{Model description and data}

LMDZ4 used in this study (Le Treut et al. 1994; Li 1999), is zoomed in East Asia (zoom center at $30^{\circ} \mathrm{N} / 110^{\circ} \mathrm{E}$, coverage $5^{\circ} \sim 55^{\circ} \mathrm{N}, 85^{\circ} \sim 135^{\circ} \mathrm{E}$ ). There are $120 \times 120$ latitude and longitude grids and 19 layers in the vertical. The spatial resolution inside the zoom is approximately $0.6^{\circ} \times 0.6^{\circ}$. The driving forcing is added through a relaxation procedure. We put a long (10 days, but not infinite, to be comparable with 
other simulations using this historical set-up) relaxation time scale inside the zoom, while the relaxation time scale is 1.5 hours outside. The use of two distinct relaxation time scales inside and outside implies that the model runs almost freely inside the zoom, whereas it totally follows the forcing outside the zoom. This operation (a long but finite time scale inside the zoom) has some similarities with the concept of spectral nudging commonly used in limited-area models for climate downscaling. But our nudging effect is very weak, and we just interpolate (with a bi-linear algorithm) global fields into the regional grid without performing any scale filtering. The main physical processes used in the model correspond to the atmospheric component of the IPSL-CM5A coupled model, as described in Hourdin et al. (2006) and Dufresne et al. (2013).

The three global climate models (GCMs) that we used as drivers are all from the $5^{\text {th }}$ Coupled Model Intercomparison Project (CMIP5) (Taylor et al. 2012). BCC-CSM1.1-m is the climate system model developed by the China Meteorological Administration, National Climate Center (Wu et al. 2013). FGOALS-g2 was developed by the Institute of Atmospheric Physics, State Key Laboratory of Numerical Modeling for Atmospheric Sciences and Geophysical Fluid Dynamics (IAP-LASG), China (Li et al. 2013). FGOALS-g2 was obviously improved in many aspects in comparison with early versions of FGOALS (Zhou et al. 2013; Yu et al. 2013). The performance of the two models has been evaluated in Zhou et al. (2014). IPSL-CM5A-MR is the last version of the global climate model developed by IPSL (Institute Pierre-Simon Laplace), France, taking part in different CMIP exercises. It generally gives a good performance at global scale or in East Asia (Chen et al. 2011a). The three selected models are quite representative of the climate modelling community. They are considered as suitable for studies of Southeast Asian climate, consensus obtained from many published works on global models evaluation (Sperber et al. 2013; Kitoh et al. 2013; Zhou et al. 2014; Jiang et al. 2015). LMDZ4 used in this study is the atmospheric circulation module in IPSL-CM5A-MR, but with different horizontal and vertical resolution.

LMDZ4 is used in its regional configuration, its main variables being nudged to 6-hourly outputs of GCMs. It is actually used as a traditional limited-area model with the whole globe as buffer zone that receives outputs of GCMs. The nudged variables include zonal wind, meridional wind, temperature and specific humidity, with a time interval of 6 hrs. The SST and sea ice prescribed as surface boundary conditions in the simulation are also from GCMs. The effective time period covers 1961-2005. Our 
downscaling approach is the largely-used one-way nesting technique, which means that there is no feedback to GCMs from the regional model. Results after downscaling are referred to as LMDZ/BCC, LMDZ/FGOALS and LMDZ/IPSL in this paper.

For the purpose of model assessment, daily temperature and rainfall at a few meteorological stations in China are used. They are quality checked and homogenized as described in $\mathrm{Xu}$ et al. (2009) and Chen et al. (2010). These two data sets are available with a resolution of $0.5^{\circ} \times 0.5^{\circ}$, for the same time period (1961-2005) of model runs. The topography of meteorological stations is provided by China Meteorological Administration (CMA). Main characteristics of models and observed data sets are listed in Table 1. The original resolution of models is preserved in the following analysis.

Fig. 1 shows the spatial resolution and surface height in different models (LMDZ, BCC, FGOALS and IPSL) in East Asia. The region roughly follows a three-step orography from east to west. The first step is the coastal plain and some hilly ground, with altitude lower than $500 \mathrm{~m}$. The second step comprises regions with mountains and hills, roughly from 500 to $3000 \mathrm{~m}$. The third step mainly refers to the Tibetan Plateau with altitudes over $3000 \mathrm{~m}$. LMDZ is characterized by a higher resolution in comparison with the other three global models. It can give more accurate coastlines and terrains. The structures of the Wuyi Mountains (Southeast China costs), the Qilian Mountains (in the north of the Tibetan Plateau, oriented from Southeast to Northwest), the Qaidam Basin (between the Tibetan Plateau and the Qilian Mountains), and the Sichuan Basin (in the east of the Tibetan Plateau) are all clearly visible and well depicted in the downscaling model. The Tarim Basin (between the Tibetan Plateau and the Tianshan Mountains) and the Junggar Basin (between the Tianshan and Altai Mountains) are at the western boundary of our zoom domain.

\section{Results and analysis}

\subsection{Temperature and Precipitation mean climatology}

Surface air temperature will be first assessed. By examining the surface air temperature among the three global models and their counterparts after downscaling, we can see that all of them are well consistent with the observation. Temperature in China is strongly affected by terrains (as shown in Fig. 2). For example, the observational temperature around the Sichuan Basin is approximately $15^{\circ} \mathrm{C}$ or more, which is evidently higher than the surrounding areas (roughly $12 \sim 15^{\circ} \mathrm{C}$ ).

Compared with observations, GCMs reproduce well the patterns of temperature 
decrease from south to north (Fig. 2). The pattern correlation coefficients between simulated and observed annual-mean temperature are 0.94, 0.92 and 0.96, respectively, for BCC, FGOALS and IPSL (as shown in Fig. 2a). The root-mean-square errors (RMSE) are $3.4^{\circ} \mathrm{C}, 4.7^{\circ} \mathrm{C}$, and $2.3^{\circ} \mathrm{C}$, respectively (Fig. 2b). However, GCMs show a weak skill of simulation in the Sichuan Basin. This is particularly true for FGOALS which does not show the warm center at all. The downscaling results show a significant improvement for the Sichuan Basin and other mountainous regions. The high-value center in the Qaidam Basin and the low-value center in the Qilian Mountains and the Tarim Basin are obviously better achieved after downscaling than those in GCMs. This improvement is a direct consequence of the higher-resolution terrain and consistent with previous works (Deque 1995; Gao et al. 2010; Shi et al. 2011; Mannig et al. 2013). Similarly, topographic structures of LMDZ4 are very well reflected in the temperature patterns, much better than in GCMs. The pattern correlation coefficients between downscaled and observed annual-mean temperature are increased to $0.98,0.97$ and 0.98 , respectively, for BCC, FGOALS and IPSL. The RMSE are decreased to $2.6^{\circ} \mathrm{C}, 3.6^{\circ} \mathrm{C}$, and $2.0^{\circ} \mathrm{C}$, respectively.

Precipitation is another important climate variable to evaluate. China experiences a typical monsoon climate and large rainfall variability in both space and time.

As revealed in observation data (Fig. 3), the annual mean precipitation in China decreases from the southeast coast to the northwest. In east China, the $3 \mathrm{~mm} /$ day rainfall intensity reaches $32^{\circ} \mathrm{N}$. The three GCMs can basically depict the main characteristics of rainfall distribution with a gradual decrease from east to west, but important biases can be noted. The spatial pattern correlation coefficients between simulated and observed precipitation are of 0.61, 0.59 and 0.62 , respectively, for BCC, FGOALS and IPSL (as shown in Fig. 3a). The RMSE are 1.19, 1.15, and 1.21 (mm/day), respectively (Fig. 3b). In BCC and IPSL, the simulated precipitation in southeast of the Tibetan Plateau is stronger than observation, while much less in southeast China and the Sichuan Basin. FGOALS simulates more precipitation on the Tibetan Plateau and in the Sichuan Basin. These precipitation defects are common in GCM simulations with coarse resolution (Li et al. 2011; Chen et al. 2011b; Jiang et al. 2012).

After downscaling, there is a significant improvement in the regions mentioned above. In particular, a high-value center in the Qilian Mountains has been reproduced as the observation shows. The pattern correlation coefficients between downscaled and observed precipitation are increased to $0.67,0.65$ and 0.69 , respectively, for BCC, 
FGOALS and IPSL. The RMSE are decreased to $1.03,0.98$, and 1.16 (mm/day), respectively. Both LMDZ/BCC and LMDZ/IPSL reduce the wet biases around northeast China and the Tibetan Plateau. LMDZ/FGOALS also improves the simulated ability in east of the Tibetan Plateau. Moreover, the dry bias of GCMs in southeast China has been reduced after downscaling.

We examine furthermore models performance in different months of the year. Figure 4 displays the spatial correlation coefficient and RMSE in function of month. For surface air temperature (Fig. 4, panels a and c), the correlation coefficient is generally smaller in summer than in winter; the RMSE does not show large variation during the year. There is a general improvement in regional simulations than in global models. FGOALS seems the less skillful for the two parameters. For precipitation (Fig. 4, panels $\mathrm{b}$ and d), both the correlation coefficient and RMSE are smaller in winter than in summer, due to the fact that this region is generally dry in winter and wet in summer.

In summary, the dynamical downscaling shows a significant improvement in the spatial distribution of both temperature and precipitation. The main patterns of temperature and precipitation over China are well depicted in the downscaling simulations. This is mainly due to a detailed terrain present in LMDZ4 for the Tibetan Plateau, the Sichuan Basin and the Qilian mountains.

\subsection{Climatic trends}

The long-term trend of a climate variable can be calculated with a simple linear regression. It consists of calculating the regression coefficient of the climate time series (temperature or precipitation) against a regularly-increasing time series $\{t=1,2, \ldots, n\}$.

$$
a_{x}=r_{x}\left(\sigma_{x} / \sigma_{t}\right)
$$

where $r_{x}$ denotes the correlation coefficient between the two time series, $\sigma_{x}, \sigma_{t}$ are their respective standard deviation. The statistical significance of $r_{x}$ can be calculated by a t-test.

The global climate was dominated by a warming trend in the 20th century (Taylor et al. 2012). Fig. 5 shows the spatial distribution of the trend evaluated from 1961 to 2005 with the annual-mean temperatures, for observations and different models respectively. Observational field presents an increasing trend of temperature in most of the country. The temperature increases much faster in the north than in the south. The warming rate in south China is lower than $0.2^{\circ} \mathrm{C} \cdot(10 \mathrm{a})^{-1}$, but that in the 
north can exceed $0.4^{\circ} \mathrm{C} \cdot(10 \mathrm{a})^{-1}$, with stronger intensity in Inner Mongolia, northeast China and east of the Tarim Basin. The observed temperature pattern is almost reproduced in the global models of BCC and FGOALS, but the amplitude is much lower than that in observation, and the high-value centers are not well depicted. The spatial distribution given by IPSL is characterized by over-estimated values in south China. Meanwhile, the significant warming in Northeast China does not appear.

After downscaling, the spatial patterns of trend in the three models are more precisely displayed. The spatial distribution of lower-in-the-south and higher-in-the-north is more consistent with observation. But the warming rate is larger in simulations than in observation, particularly in Northeast China, where the warming rate exceeds $0.6^{\circ} \mathrm{C} \cdot(10 \mathrm{a})^{-1}$. Simulated trends in central and south China in LMDZ/BCC and LMDZ/IPSL are also higher than their counterparts in observation.

Observed trend of annual-mean precipitation from 1961 to 2005 shows a decrease over North China, but an increase in the middle and lower reaches of the Yangtze River and in the coastal areas of south China (as shown in Fig. 6). This result is in a general agreement with previous studies which show a contrasting pattern of precipitation trend in east China: wet in the south and dry in the north (Zou et al. 2010).

The ability of models in simulating precipitation is generally weaker than that in simulating surface air temperature. Simulated trend for precipitation is still far from realistic, although the situation for temperature is more consistent with observation (shown in Fig. 6). Results from different GCMs all revealed a sharp increase in north China, but a decrease in the Yangtze-Huaihe river basin, especially for FGOALS and IPSL, which are almost contrary to the observation. Compared to the previous exercise in CMIP3, the ability of simulating interannual variability and seasonal cycle of East Asian summer monsoon has been largely enhanced in CMIP5 (Sperber et al. 2012; Flato et al. 2013). However, for rainfall, there are still important uncertainties and differences among GCMs (Jiang et al. 2013; Zhang et al. 2013). After downscaling, all the three models show a gradually decreasing trend of precipitation in north China, but still significantly different from observation. LMDZ/IPSL reproduces the increasing trend in the Yangtze-Huaihe drainage basins. It performs much better than IPSL, its counterpart of global models.

Figures 5 and 6 show an obvious advantage for LMDZ4. The regional simulations are closer to each other than to the respective driving GCMs. For example, the three downscaled simulations show a meridional gradient of warming in line with 
observations, while the driving GCMs miss it completely (Fig. 5). Similar phenomenon for the precipitation trends (Fig. 6). Trend patterns in the regional runs are generally different from those in GCMs, but closer to each other. That is because, in our experiment, LMDZ4 conducts quite freely inside the target area $\left(5^{\circ} \sim 55^{\circ} \mathrm{N}\right.$, $85^{\circ} \sim 135^{\circ} \mathrm{E}$ ) with very weak forcing from GCMs. The relaxation time scale is 10 days inside the entire zoom. This corresponds to a week nudging used in some limited-area models. So the three downscaled simulations are more resemblant to each other than to their respective driving GCMs.

Based on the above comparative studies before and after the downscaling, there is an impressive ability for temperature, but feeble skill in GCMs for the simulated precipitation. Moreover, for both surface air temperature and precipitation, the good regions for climate means are not necessarily the good areas for trends.

\subsection{Validation in sub-regions}

Due to significant regional differences of climate in China, it is useful to divide China into a few sub-regions. The regional division is shown in Fig.1a for 6 sub-regions, reflecting the increasing continental characteristics of climate from east to west, as well as the south-north gradient and the main orographic features. The sub-regions are Northeast China (NE), North China (NC), Yangtze river basin (YZ), Southeast China (SE), Southwest China (SW) and Northwest China (NW).

Unlike for long-term trend, it is not relevant to compare simulated sequences against observed ones, especially for the interannual time scale. However, it is adequate to compare their statistical behaviors from each other. Figure 7 shows such statistical properties (in the form of box-and-whisker plots) of annual-mean temperature during the period 1961-2005. Each panel shows the area average of the corresponding sub-region.

On the whole, the medians (quantity separating the higher half from the lower half of the distribution) of GCMs and downscaling runs are generally smaller than that of the observation, which indicates a cold bias in most regions, except in NC and SE. In NE, NW and SW, the median temperatures in downscaling runs are more accurate than those in GCMs. The median temperatures in downscaling runs in NE, $\mathrm{YZ}$ and SE are closer to observation than those in other sub-regions, and the median biases are smaller than $2^{\circ} \mathrm{C}$. We can however see that, the minimum and maximum values (represented by the whiskers) in simulated temperatures do not show significant changes after the downscaling. 
Compared to temperature, rainfall in the dynamical downscaling simulation has a more obvious positive effect (Figure 8), especially in NE, NW and SW. The wet biases in GCMs over most areas range from $20 \%$ to $100 \%$, with some areas exceeding $150 \%$. The downscaled rainfalls have a reduced bias in median values. Both GCMs and regional simulations have a wet bias in west areas with complex terrain. Earlier studies have shown that the reason lies within the upwind effect, which is even stronger with a better-resolved topography (Mannig et al. 2013). It should be noted that rainfall simulation in climate models is still an issue of grand challenge, since there are many processes controlling the macro-properties and micro-physics of clouds and precipitations, but missing in current parameterizations. Moreover, the lack of a high-quality and high-resolution observed rainfall dataset contributes to the persistency of uncertainties in models, and makes models evaluation a very challenging issue (You, 2012).

China, strongly affected by the East Asian Monsoon, presents a strong seasonal cycle in both temperature and rainfall. Therefore, it is necessary to evaluate the simulation capacity of GCMs and downscaling models in terms of seasonal changes. Figure 9 shows the seasonal cycle of temperature in different regions from observation, GCMs and downscaled simulations respectively. It can be learned that, the maximum temperature difference between summer and winter appears in Northeast, approaching $40^{\circ} \mathrm{C}$. The primary cause is its high-latitude location, where under the control of the Siberia cold high-pressure in winter, the temperature is as low as $-20^{\circ} \mathrm{C}$, while in summer it exceeds $20^{\circ} \mathrm{C}$ because of the East Asian summer monsoon. In North China, models present a relatively small deviation. They are close to the observation. All the simulated temperatures in the Yangtze River basin are higher in summer and lower in winter than the observation. Southeast China has a similar situation except that the temperature in LMDZ/FGOALS has a cold bias all year round. Temperatures among most models in Northwest and Southwest are lower throughout the year, except for some models (LMDZ/BCC and LMDZ/IPSL) showing higher temperature in summer. All downscaled results are closer to observation than GCMs. For all sub-regions, whatever GCMs or downscaled simulations, September and October show the best performance.

For precipitation, the seasonal cycles from different regions show a broad range of characteristics (see Fig. 10). A common behavior is, however, that rainfalls peak in summer for all sub-regions. Northeast and North China show the most remarkable seasonal cycle with peaks in July, accompanied with rapid transitions in June and 
August (Fig. 10, NE and NC). All simulations seem able to reproduce such characteristics in these two regions. But they have a general dry bias in summer, while a wet bias in other seasons. IPSL in Northeast China and FGOALS in North China are exceptions, showing smaller deviations after downscaling.

In the Yangtze river basin, the observed precipitation peaks in July, while all GCMs and downscaled maxima appear in May with an advance in phase (except for IPSL), and precipitation intensity is weaker in summer, autumn and winter, but stronger in spring. In Southeast China, precipitations peak in June, but most simulations show a phase shift to July or a too-broad distribution from May to August. Precipitation amounts in all simulations are generally smaller than the observed values (see Fig.10 SE).

The mountainous regions in Southwest and Northwest China (Fig. 10, SW and NW) with their complex terrain show large differences for each model throughout the year. All the models overestimate precipitation in these two regions, while the three downscaling simulations show significant improvements. This is particularly true for the model FGOALS running with a lower resolution.

To quantify the above comparison, we calculate the correlation coefficient and the RMSE for each curve in Fig. 10 with their counterpart from observation (black curve in Fig. 10). Results (Table 2) show that there is a general improvement from GCMs to regional simulations in terms of RMSE, but not always correlation coefficient. This means that LMDZ-regional has a better mean climatology, but its seasonal match, controlled by GCMs, is not ameliorated. We also observe the same results for the surface air temperature (mean climatology improved, but not the seasonal match itself; results not shown).

In summary, models show different performances in different sub-regions. Consistent with previous studies (Zhou et al. 2002; Chen et al. 2011; Jiang et al. 2013), most GCMs have a poor skill in terms of precipitation in west China (especially the Tibet Plateau). Encouragingly in our study, for both temperature and precipitation, the dynamical downscaling simulations are generally closer to observations. Among the three GCMs, the downscaling simulation from FGOALS shows the most obvious improvements. For both temperature and rainfall, the superiority of dynamical downscaling is deeply dependent on topography. Especially over the complex terrain in China, the dynamical downscaling has a more powerful capacity than GCMs.

\subsection{Orographic effects}


Our previous analysis shows clearly that a dynamical downscaling gives important improvements in complex-terrain regions in Southwest and Northwest China. The observational data at meteorological stations can be regarded as the "ground truth", which help us to examine GCMs and downscaling performances in more details. We select 25 stations covering the transition from wet coastal regions to dry inland areas (see Fig. 11).

It can be seen that almost all elevations in GCMs and LMDZ4 are higher than the real elevation. This is due to the fact that terrain in models is of mean topography, but meteorological stations are generally located in valleys or low-land areas. The terrain height deviations (see $\triangle \mathrm{EL}$, simulations minus observations) for stations in west China are generally larger. For most stations with low altitude in east China, the surface height in LMDZ4 is closer to observed elevation than GCMs (as shown in Table 3).

By comparing temperatures from GCMs and downscaled simulations, it is found that the average temperature bias at the 25 stations is reduced after downscaling, with absolute value $2.53^{\circ} \mathrm{C}$ in $\mathrm{GCMs}$ against $1.13^{\circ} \mathrm{C}$ in downscaled simulations, except for Fuzhou, Xichang, Kunming and Urumqi (see $\triangle T$ ). Bias of simulated temperature is usually proportional to the increase of local height. The accuracy of temperature simulation depends on altitudes (Zhao et al. 2008).

To investigate quantitatively the topographic effects on simulated temperature, we perform a topographic correction, in a similar way as used in a land-data-assimilation system (Cosgrove et al. 2003). Temperatures from models at each station are adjusted with the following algorithm:

$$
T_{\text {corr }}=T_{\text {sim }}+\mu \Delta H
$$

where $T_{\text {cor }}$ is the temperature $\left({ }^{\circ} \mathrm{C}\right)$ after correction, and $T_{\text {sim }}$ the simulated one $\left({ }^{\circ} \mathrm{C}\right)$ before correction; $\mu$ is the lapse rate (assumed to be $0.65^{\circ} \mathrm{C} / 100 \mathrm{~m}$ ), and $\Delta H$ the difference of elevations $(\mathrm{m})$ between models and the true topography.

Corrections from GCMs and regional simulations are all shown in Table $3(\triangle$ T-cor). For GCMs, the absolute value of temperature bias after topographic correction is reduced to $1.09^{\circ} \mathrm{C}$ (against $2.53^{\circ} \mathrm{C}$ before correction). The temperature bias of the regional simulations is $1.13^{\circ} \mathrm{C}$. The bias becomes $0.98^{\circ} \mathrm{C}$ if the same bias correction is applied. It is evident that, for temperature, the topographic correction plays a role in GCMs as well as in the dynamical downscaling simulations. This correction leads to temperatures closer to the observation. From $\triangle T$ and $\triangle T$-cor, we can also observe that, in western high-altitude stations like Lhasa, Xi'an, Lanzhou, Xining, Yinchuan 
with strong biases in GCMs, the effects of topographic correction are also more spectacular than that in eastern low-altitude stations like Harbin, Shenyang, Chifeng, Jinan, Nanjing, etc. In agreement with previous studies, our results confirm that the simulated temperature is highly dependent on altitude of model grids and on complexity of model topography. This general behavior should be primarily taken into account for any applications of model outputs to studies of climate change impacts.

For precipitations, Table 3 shows that GCMs generally have over-estimations at stations in wet basins in the east, but under-estimations along the western mountain ranges. The average precipitation bias for the 25 stations is reduced after downscaling, with a relative error of $35.8 \%$ in GCMs and $28.2 \%$ in regional simulations. The amelioration provided by the dynamical downscaling is furthermore revealed different for east and west regions. Some high-altitude stations like Lhasa, Lanzhou, Xining, Yinchuan and Yushu, with serious wet bias in GCMs, have the most significant amelioration after downscaling. Table 3 also reveals that the simulated precipitation deviations are relative to the elevation of stations for both GCMs and downscaling simulations, the higher elevation the larger deviation. Unlike the surface air temperature that can be partly corrected by considering the terrain height, precipitation cannot be simply corrected without considering changes in the regional or local atmospheric general circulation (Tippett et al. 2003).

Since surface air temperature and precipitation are strongly controlled by atmospheric circulation, their amelioration in downscaling simulations should be accompanied with amelioration in atmospheric dynamic fields, such as wind and geopotential height (GHT). Figure 12 (left two panels) shows geopotential height at $500 \mathrm{hPa}$ and winds at $850 \mathrm{hPa}$, as depicted in ERA-Interim, for summer and winter respectively. Mean biases of GCMs (middle) and downscaling simulations (right) are also shown. For both summer and winter, there is some resemblance between GCMs and downscaling simulations, due to the nudging relationship between them. This resemblance is found larger in winter than in summer, which can be explained by the fact that winter climate in the region is much more controlled by large-scale circulation in comparison to summer regional climate. Many regional events can develop in summer without necessarily a corresponding large-scale structure, especially when convection is dominant .

Let us now examine further the summer situation. The GCMs bias is consistent with a general imperfection in many models, with a too-strong south wind system in East China, making the summer monsoon too much inland. This bias is largely 
reduced in downscaling simulations. We believe that the amelioration of atmospheric circulation in the downscaling simulation brings a significant improvement for both surface air temperature and precipitation.

In summary, because the downscaling model LMDZ4 has a higher resolution and a more accurate representation of the underlying terrain, surface air temperature is generally better in LMDZ4 than in GCMs. The topographic correction plays a role in GCMs as well as in the dynamical downscaling simulations. However, the orographic effect is not the only reason why the dynamical downscaling performs better, the amelioration of the atmospheric general circulation at regional or local scale certainly plays its role.

Our results are consistent with those presented in Gao et al. (2006) who studied the performance of a limited-area climate model running over East Asia, in function of different model horizontal resolutions. They also tried to isolate the topographic effect from that of the resolution. They showed that the first contributor for a better simulation of precipitation in East Asia is the increase of model resolution. This resolution effect is more important than that from a better description of the surface topography which is only a second contributor.

\section{Summary and Conclusion}

Three global models, BCC-csm1-1-m, FGOALS-g2 and IPSL-CM5A-MR, were used to drive a variable grid atmospheric general circulation model LMDZ4, to produce an ensemble of dynamical downscaling simulations in East Asia. Simulations cover the present-day period (1961-2005). The research in this study is, primarily, of practical significance for developing and validating suitable regional climate model system in eastern China. The performance of GCMs and downscaling simulations has been evaluated in terms of precipitation and surface air temperature in China. We compared their mean climatology and long-term trend.

In general, GCMs and downscaling models are all able to reproduce the main spatial patterns of temperature and precipitation over China. Compared to GCMs, the intensity and location of simulated temperature and precipitation from LMDZ4 are closer to observations. The spatial pattern correlation coefficient calculated for the annual-mean temperature varies from $0.92 / 0.94$ in GCMs to $0.97 / 0.98$ in downscaling simulations. The same indicator for rainfall varies from $0.59 / 0.62$ to $0.67 / 0.69$. The root mean square errors also significantly decrease from GCMs to regional simulations for both temperature and precipitation. The downscaling with FGOALS 
exhibits the most significant improvement, compared with BCC and IPSL. This is due to the fact that FGOALS has the lowest spatial resolution and the downscaling shows its most visible added-value.

For long-term trend from 1961 to 2005, a general warming is observed over China with minimum amplitude near the coasts and stronger amplitude inland. All GCM and regional simulations catch the warming trend. But the spatial patterns are not always consistent with the observed one. For rainfall, there is a dipole structure in East China: wet conditions in the south and dry conditions in the north. This structure does not seem to be reproduced, neither in GCMs nor in regional simulations. We note however that the three regional runs present some similar structures, although their counterpart in GCMs is quite different: dry in Northeast China and South China, but weak wet conditions in North China. Simulation in precipitation tendency was inferior to that in temperature. Deficiency in the trend simulation has received more and more concerns in climate models currently (Wang et al. 2013; Dong et al. 2013; Dong and Zhou. 2013). That requires the comparison of multi-GCM or RCM ensembles (Gao et al. 2012b). The CORDEX project which we are taking part in will help to understand uncertainties of climate changes including both historical period and future projections (Giorgi et al. 2009).

We also divided China into 6 sub-regions and investigated the statistical properties of regional-mean temperature and precipitation. Results are displayed in the form of box-and-whisker plots allowing us to evaluate the median values and the extrema (minimum and maximum). For both temperature and precipitation, medians seem improved from GCMs to downscaling simulations; but the range of extrema does not show significant changes.

Seasonal evolution for the 6 sub-regions is examined and compared to observations. We did not observe an obvious improvement in terms of monthly correlation coefficient. But the RMSE is generally ameliorated in the downscaling simulations, for both surface air temperature and precipitation.

We believe that the good general performance of downscaling simulations resides (partly at least) in their higher resolution and the good representation of the terrain. We select 25 representative stations to validate simulations. The terrain in downscaling simulations is closer to the real topography; deviations of both precipitation and temperature are reduced. We also developed a simple algorithm of topographic correction to ameliorate surface air temperature at station level. It is primarily destined to provide relevant information for climate impact studies. But it 
goes to the idea that a refined description of the terrain was one of the vital factors leading to the superiority of downscaling simulations (Giorgi et al. 2004). Unfortunately, there is no simple algorithm possible of terrain correction for precipitation.

This paper mainly focuses on the added-value of LMDZ4 in its regional configuration in comparison to its drivers, outputs from GCMs. It is worth to note that other validation works of LMDZ4 over East Asia were also reported with re-analyses (ERA-40 or ERA-Interim) as drivers (Zou et al. 2010, Yang et al. 2015). Such simulations, in the "perfect boundary condition" mode, did show a good model performance of LMDZ4 in capturing both the sign and magnitude of temperature and precipitation anomalies.

An inter-comparison is planned for our next works to understand errors in regional simulations and attribute them to imperfections in either large-scale boundary conditions or physical parametrizations in LMDZ4. Finally we need to point out that the lack of a reliable observation dataset also contributes to uncertainties for evaluating high-resolution climate models.

\section{Acknowledgments:}

This work is supported jointly by the National Natural Science Foundation of China (Grant No. 41230528), National Program on Key Basic Research Project of China (Grant No. 2012CB955204), China R\&D Special Fund for Public Welfare Industry (meteorology) (GYHY201306024) and a Project Funded by the Priority Academic Program Development (PAPD) of Jiangsu Higher Education Institutions. Helpful comments from the anonymous reviewers are greatly appreciated.

\section{References:}

Carril A, Menendez C, Remedio A, Robledo F, Sorensson A, Tencer B, Boulanger JP, de Castro M, Jacob D, Le Treut H, Li L, Penalba O, Pfeifer S, Rusticucci M, Salio P, Samuelsson P, Sanchez E, Zaninelli P (2012) Assessment of a multi-RCM ensemble for South America. Climate Dynamics, 39, 2747-2768.

Chen D, Ou T, Gong L, Xu CY, Li W, Ho CH, Qian W (2010) Spatial interpolation of daily precipitation in China: 1951-2005. Adv Atmos Sci 27(6) : 1221-1232. doi: 10.1007/s00376-010-9151-y

Chen W, Jiang Z, Li L, Yiou P (2011a) Simulation of regional climate change under the IPCC A2 
scenario in southeast China, Clim Dyn 36: 491-507

Chen W, Jiang Z, Li L (2011b) Probabilistic projections of climate change over China under the SRES A1B scenario using 28 AOGCMs, J Clim 24: 4741-4756. DOI: 10.1175/2011JCLI4102.1

Cosgrove, B. A., and Coauthors (2003) Real-time and retrospective forcing in the North American Land Data Assimilation Systems (NLDAS) project. J Geophys Res, 108, 8842, doi:10.1029/2002JD003118.

Deque M, Piedelievre JP (1995) High resolution climate simulation over Europe. Clim Dyn 11: 321-340

Dong M, Wu T, Wang Z (2013) Simulation of the Precipitation and Its Variation During the $20^{\text {th }}$ Century Using the BCC Climate Model (BCC_CSM1.0). Journal of applied meteorological science 24(1):1-11 (in Chinese)

Dong L, Zhou T (2013) Steric sea level change in twentieth century historical climate simulation and IPCC-RCP8.5 scenario projection: A comparison of two versions of the FGOALS model. Adv Atmos Sci 30(3): 841-854, doi:10.1007/s00376-012-2224-3

Dufresne JL, and co-authors (2013) Climate change projections using the IPSL-CM5 Earth System Model: from CMIP3 to CMIP5. Climate Dynamics, 40, 2123-2165. DOI: $10.1007 / \mathrm{s} 00382-012-1636-1$

Flato et al. (2013) IPCC AR5 Chapter 9: Evaluation of Climate Models.

Frei C, Schöll R, Fukutome S, Schmidli J, Vidale PL (2006) Future change of precipitation extremes in Europe: Intercomparison of scenarios from regional climate models. J Geophys Res 111: D06105 doi:10.1029/2005JD005965

Gao XJ, Xu Y, Zhao ZC (2006) On the role of resolution and topography in the simulation of east Asia precipitation. Theor. Appl. Climatol., 86: 173-185.

Gao XJ, Shi Y, Giorgi F. (2010) A high resolution simulation of climate change over China. Sci China Earth Sci 40(7): 911-922 (in Chinese)

Gao XJ, Shi Y, Zhang DF (2012a) Climate change in China in the 21st century as simulated by a high resolution regional climate model. Chin Sci Bull 57: 374-381. (in Chinese)

Gao XJ, et al (2012b) Uncertainties in monsoon precipitation projections over China: results from two high-resolution RCM simulations. Climate Research 52: 213-226

Giorgi F, Bi X, Pal J.S. (2004) Mean, interannual variability and trends in a regional climate change experiment over Europe. I. Present-day climate (1961-1990). Climate Dynamics 22: 733-756 
Giorgi F, Jones C, Asrar GR. (2009) Addressing climate information needs at the regional level: the CORDEX framework. WMO Bulletin, 58(3): 175-183.

Goubanova K, Li L (2007) Extremes in temperature and precipitation around the Mediterranean basin in an ensemble of future climate scenario simulations. Global and Planetary Change $57: 27-42$

Guo Y, Li J, and Li Y (2012) A time-scale decomposition approach to statistically downscale summer rainfall over North China. J. Climate, 25, 572-591.

Guo Y, Li J and Li Y (2014) Seasonal forecasting of North China summer rainfall using a statistical downscaling model. J. Appl. Meteor. Climatol., 53, 1739-1749

Hourdin F and co-authors (2006) The LMDZ4 general circulation model: climate performance and sensitivity to parametrized physics with emphasis on tropical convection. Climate Dynamics, 27, 787-813.

IPCC (2007) Regional climate projection. Climate Change 2007: The Physical Science Basis. Contribution of Working Group I to the Fourth Assessment Report of the Intergovernmental Panel on Climate Change, S. Solomon et al., Eds., Cambridge University Press, Cambridge, UK and New York, NY, USA,849-926.

Jiang D B, Tian Z P. (2013) East Asian monsoon change for the 21st century: Results of CMIP3 and CMIP5 models. Chin Sci Bull, 58, doi: 10.1007/s11434-012-5533-0

Jiang Z, Song J, Li L and Chen W (2012) Extreme climate events in China: IPCC-AR4 model evaluation and projection, Climatic Change 110:385-401, doi: 10.1007/s10584-011-0090-0

Jiang Z, Li W, Xu J and Li L (2015) Extreme Precipitation Indices over China in CMIP5 models. Part 1: Models evaluation. J Climate. 28, 8603-8619.

Kitoh A, H Endo, Kumar K, et al (2013) Monsoons in a changing world: A regional perspective in a global context. J Geophys Res Atmos, 118, 3053-3065, doi: 10.1002/jgrd.50258.

Le Treut H, Li Z, Forichon M (1994) Sensitivity of the LMD general circulation model to greenhouse forcing associated with two different cloud water parameterizations. J Clim 7: $1827-1841$

L'Hévéder B, Li L, Sevault F, Somot S (2013) Interannual variability of deep convection in the Northwestern Mediterranean simulated with a coupled AORCM. Climate Dynamics, 41, 937-960.

Li H, Feng L, and Zhou T (2011) Multi-model projection of July-August climate extreme changes over China under CO2 doubling. Part I: Precipitation. Adv Atmos Sci., 28(2), 433-447, doi:10.1007/s00376-010-0013-4

Li L, Lin P, Yu Y, et al, (2013) The Flexible Global Ocean-Atmosphere-Land System Model: Version g2: FGOALS-g2. Atmos. Adv. Sci. 30(3):543-560 
Li Z (1999) Ensemble atmospheric GCM simulation of climate interannual variability from 1979 to 1994. J Clim 12:986-1001

Li Z (2006) Atmospheric GCM response to an idealized anomaly of the Mediterranean sea surface temperature. Climate Dynamics, 27, 543-552.

Mannig B, Müller M, Starke E, Merkenschlager C, Mao W, Zhi X, Podzun R, Jacob D, Paeth H (2013) Dynamical downscaling of climate change in Central Asia. Glob Planet Change 110:26-39

Rojas M, Li LZ, Kanakidou M, Hatzianastassiou N, Seze G, Le Treut H (2013) Winter weather regimes over the Mediterranean region: their role for the regional climate and projected changes in the 21st century. Climate Dynamics, 41, 551-571.

Shi Y, Gao X, Wu J, Giorgi F (2011) Changes in snow cover over China in the 21st century as simulated by a high resolution regional climate model. Environ Res Lett 6, doi:10.1088/1748-9326/6/4/045401

Solman S, Sanchez E, Samuelsson P, da Rocha R, Li L, Marengo J, Pessacg N, Remedio ARC, Chou SC, Berbery H, Le Treut H, de Castroand M, Jacob D (2013) Evaluation of an ensemble of regional climate model simulations over South America driven by the ERA-Interim reanalysis: Model performance and uncertainties. Climate Dynamics, 41, $1139-1157$

Sperber KR, Annamalai H, Kang I-S, Kitoh A, Moise A, Turner A, Wang B, Zhou T (2013) The Asian summer monsoon: an intercomparison of CMIP5 vs. CMIP3 simulations of the late 20th century. Clim Dyn 1-34, doi: 10.1007/s00382-012-1607-6

Taylor KE, Stouffer RJ, Meehl GA (2012) An overview of CMIP5 and the experiment design. Bull Am Meteorol Soc doi:10.1175/BAMS-D-11-00094.1

Tippett MK, Barlow M, Lyon B (2003) Statistical correction of central southwest Asia winter precipitation simulations. Int J Climatol 23, 1421-1433.

van Vuuren DP, Edmonds J, Kainuma M, Riahi K, Thomson A, Hibbard K, Hurtt GC, Kram T, et al (2011) The representative concentration pathways: an overview. Climatic Change 109:5-31

Vautard R, Noël T, Li L, Vrac M, Martin E, Dandin P, Cattiaux J, Joussaume S (2013) Climate variability and trends in downscaled high-resolution simulations and projections over Metropolitan France. Climate Dynamics, 41, 1419-1437.

Wang S, Yu E (2013) Dynamical downscaling simulation over China using the nested MIROC/WRF model. Climatic and Environmental Research 18 (6): 681-692. (in Chinese)

Wu T, Li W, Ji J, Xin X, Li L, Zhang F, Wei M, Shi X (2013) Global carbon budgets simulated by the Beijing Climate Center Climate System Model for the last century. J Geophys Res Atmos 118, 1-22, doi:10.1002/jgrd.50320 
646

647

648

649

650

651

652

653

654

655

656

657

658

659

660

661

662

663

664

665

666

667

668

669

670

671

672

673

674

675

676

677

Xu Y, Gao X, Shen Y (2009) A daily temperature dataset over China and its application in validating a RCM simulation. Adv Atmos Sci 26(4): 763-772

Xu Y, Xu C. (2012) Preliminary assessment of simulations of climate changes over China by CMIP5 multi-models. Atmospheric and Oceanic Science Letters, 5: 489-494.

Yang H, Jiang ZH, Li L (2015) Simulation of the East Asian Summer Climate with a Variable Resolution Model LMDZ4. Transactions of Atmospheric Sciences (in Chinese)

You Q, Fraedrich K, Ren G, Ye B, Meng X, Kang S (2012) Inconsistencies of precipitation in the eastern and central Tibetan Plateau between surface adjusted data and reanalysis. Theor Appl Climatol 109:485-496.

Yu Y, He J, Zheng W, Luan Y (2013) Annual Cycle and Interannual Variability in the Tropical Pacific by three versions of FGOALS. Adv Atmos Sci 30(3):621-637, doi:10.1007/s00376-013-2184-2

Zhang D, Shi Y (2012) Numerical simulation of Climate Changes over North China by the RegCM3 model. Chinese J. Geophys, 55(9):2854-2866. (in Chinese)

Zhang J, L Li, T J Zhou, and X.G. Xin (2013) Evalution of Spring Persistent Rainfall over East Asia in CMIP3/CMIP5 AGCM simulations. Advances in Atmospheric Science. 30(6): 1587-1600

Zhao T, Guo W, Fu C (2008) Calibrating and evaluating reanalysis surface temperature error by topographic correction. J Clim, 21:1440-1446.

Zhou T, Li Z (2002) Simulation of the East Asian summer monsoon using a variable resolution atmospheric GCM . Clim Dyn 19: 167-180

Zhou T, and Yu R (2006) Twentieth century surface air temperature over China and the globe simulated by coupled climate models. J. Climate, 19, 5843-5858.

Zhou T, Song F, Chen X (2013) Historical evolution of global and regional surface air temperature simulated by FGOALS-s2 and FGOALS-g2: How reliable are the model results? Adv Atmos Sci 30(3): 638-657

Zhou T, Chen X, Dong L, et al. (2014) Chinese contribution to CMIP5: An overview of five Chinese models' performances. J Meteor Res, 28(4), 481-509.

Zou L, Zhou T, Li Z, et al. (2010) East China Summer Rainfall Variability of 1958-2000: Dynamical Downscaling with a Variable-Resolution AGCM. J. Climate, 23:6394-6408 


\section{Table Captions}

Table 1 Sources of models and data

Table 2 Correlation coefficients and root-mean-square error (RMSE) (unit: mm/day) to measure the seasonal match between the observed and simulated precipitations for six sub-regions in China and three pairs of global/regional simulations. Figures in bold in the regional simulation columns indicate improvement (higher correlation or lower RMSE) compared to their counterparts in global models.

Table 3 Weather stations details: EL (m) is the elevation of station; $\triangle \mathrm{EL}(\mathrm{m}), \triangle \mathrm{T}$ $\left({ }^{\circ} \mathrm{C}\right)$ and $\triangle \operatorname{Pr}(\%)$ are the differences of model elevation, simulated temperature and precipitation with the true terrain, observed temperature and precipitation, respectively. $\triangle \mathrm{T}$-cor $\left({ }^{\circ} \mathrm{C}\right)$ is the same as $\triangle \mathrm{T}\left({ }^{\circ} \mathrm{C}\right)$, but for topography-corrected temperature. GCM-ave stands for the average of BCC, FGOALS and IPSL, RCM-ave stands for the average of LMDZ/BCC, LMDZ/FGOALS and LMDZ/IPSL. Figures in bold in the regional simulation columns indicate improvement compared to their counterparts in global models.

\section{Figure Captions}

Fig.1 Grid (in the form of mosaic) and surface orography (bottom color shading in $\mathrm{m}$ ) of models (a) LMDZ, (b) BCC, (c) FGOALS, (d) IPSL in East Asia

Fig.2 Distribution of annual-mean temperature $\left({ }^{\circ} \mathrm{C}\right)$ during 1961-2005 from observation (top), GCMs (middle row, BCC, FGOALS, IPSL) and downscaling simulations (bottom row, LMDZ/BCC, LMDZ/FGOALS, LMDZ/IPSL) over China. Spatial-pattern correlation coefficients and root-mean-square error (RMSE) between the observed and simulated fields are given in panels a and $b$.

Fig. 3 Same as Fig. 2, but for precipitation (mm/day).

Fig. 4 Seasonal evolution of Spatial-pattern (a, b) correlation coefficients and (c, d) root-mean-square error (RMSE) between the observed fields and simulated ones for (a, c) temperature and $(b, d)$ precipitation.

Fig. 5 Long-term trend of annual-mean temperature (units: ${ }^{\circ} \mathrm{C} \cdot(\mathrm{a})^{-1}$, stippling indicates areas where the trend is statistically significant at the $95 \%$ confidence level). The layout of panels is the same as in Fig. 2: observation on the top, GCMs in the middle and downscaling simulations on the bottom.

Fig. 6 Same as Fig. 5, but for long-term trend of annual precipitation (units: $(\mathrm{mm} / \mathrm{d}) \cdot(\mathrm{a})^{-1}$, stippling indicates areas where the trend is statistically significant at the $95 \%$ confidence level). 
713 Fig. 7 Distribution of annual temperature during 1961-2005 for different data sets and 714 different regions. These, box and whisker plots show the median (“+”), inter-quartile 715 range, maximum and minimum of temperatures respectively (unit: ${ }^{\circ} \mathrm{C}$ ).

716 Fig. 8 Same as Fig. 7, but for the annual precipitation (unit: $\mathrm{mm} /$ day).

717 Fig.9 Seasonal cycle of monthly-mean temperature $\left({ }^{\circ} \mathrm{C}\right)$ during 1961-2005 for 718 different data sets and different regions.

719 Fig. 10 Same as Fig. 9, but for the seasonal cycle of precipitation (mm/day).

720 Fig. 11 Geographic positions of the 25 representative stations in China

721 Fig. 12 Climatological mean of geopotential height at $500 \mathrm{hPa}$ (contours, unit: dagpm) 722 and winds at $850 \mathrm{hPa}$ (vectors, unit: $\mathrm{m} / \mathrm{s}$ ) for (a,d) ERA-interim and biases in (b,e) 723 GCMs-ave and (c,f) RCMs-ave (a, b, c for summer, d, e, f for winter). 
Table1 Sources of models and data

\begin{tabular}{lllll}
\hline \multicolumn{1}{c}{ Data } & Source & Time & Resolution \\
\hline \multirow{4}{*}{ Model } & LMDZ4 & France, LMD & $1961-2005$ & $0.6 \times 0.6$ \\
& BCC-csm1-1-m & China, BCC & $1961-2005$ & $1.125 \times 1.125$ \\
& FGOALS-g2 & China, IAP & $1961-2005$ & $2.8125 \times 2.8125$ \\
& IPSL-CM5A-MR & France, IPSL & $1961-2005$ & $2.5 \times 1.2676$ \\
\hline \multirow{4}{*}{ Obs } & Precipitation & Chen et al, 2010 & $1961-2005$ & $0.5 \times 0.5$ \\
& Temperature & Xu et al, 2009 & $1961-2005$ & $0.5 \times 0.5$ \\
& Elevation & China, CMA & & Station \\
\hline
\end{tabular}

726

727 
Table 2. Correlation coefficients and root-mean-square error (RMSE) (unit: $\mathrm{mm} / \mathrm{day}$ ) to measure the seasonal match between the observed and simulated precipitations for six sub-regions in China and three pairs of global/regional simulations. Figures in bold in the regional simulation columns indicate improvement (higher correlation or lower RMSE) compared to their counterparts in global models.

\begin{tabular}{lllllll}
\hline & BCC & $\begin{array}{l}\text { LMDZ/ } \\
\text { BCC }\end{array}$ & FGOALS & $\begin{array}{l}\text { LMDZ/ } \\
\text { FGOALS }\end{array}$ & IPSL & $\begin{array}{l}\text { LMDZ/ } \\
\text { IPSL }\end{array}$ \\
\hline & Corr (RMSE) & Corr (RMSE) & Corr (RMSE) & Corr (RMSE) & Corr (RMSE) & Corr (RMSE) \\
\hline NE & $0.97(0.58)$ & $0.94(0.82)$ & $0.97(0.58)$ & $0.96(0.66)$ & $0.99(0.91)$ & $0.95(\mathbf{0 . 6 9})$ \\
NC & $0.96(0.42)$ & $0.96(\mathbf{0 . 3 5})$ & $0.93(0.90)$ & $\mathbf{0 . 9 7}(\mathbf{0 . 4 0})$ & $0.97(0.31)$ & $0.96(0.37)$ \\
YZ & $0.86(1.21)$ & $\mathbf{0 . 9 0}(\mathbf{0 . 9 3})$ & $0.85(0.89)$ & $\mathbf{0 . 8 6}(1.09)$ & $0.95(0.75)$ & $0.94(\mathbf{0 . 6 5})$ \\
SE & $0.97(1.87)$ & $0.97(\mathbf{1 . 4 6})$ & $0.85(1.83)$ & $\mathbf{0 . 9 8}(\mathbf{1 . 0 1})$ & $0.83(1.74)$ & $\mathbf{0 . 9 3}(\mathbf{1 . 3 0})$ \\
NW & $0.86(0.76)$ & $0.83(\mathbf{0 . 4 0})$ & $0.82(0.99)$ & $0.68(\mathbf{0 . 5 1})$ & $0.95(0.47)$ & $0.94(\mathbf{0 . 3 9})$ \\
SW & $0.93(1.71)$ & $0.86(\mathbf{0 . 8 9})$ & $0.97(1.46)$ & $0.92(\mathbf{0 . 6 4})$ & $0.97(1.25)$ & $\mathbf{0 . 9 8}(\mathbf{0 . 8 3})$ \\
\hline
\end{tabular}


Table 3 Weather stations details: EL (m) is the elevation of station; $\triangle \mathrm{EL}(\mathrm{m}), \triangle \mathrm{T}\left({ }^{\circ} \mathrm{C}\right)$ and $\triangle \operatorname{Pr}$

$737(\%)$ are the differences of model elevation, simulated temperature and precipitation with the true 738 terrain, observed temperature and precipitation, respectively. $\triangle \mathrm{T}$-cor $\left({ }^{\circ} \mathrm{C}\right)$ is the same as $\triangle \mathrm{T}\left({ }^{\circ} \mathrm{C}\right)$, 739 but for topography-corrected temperature. GCM-ave stands for the average of BCC, FGOALS and 740 IPSL, RCM-ave stands for the average of LMDZ/BCC, LMDZ/FGOALS and LMDZ/IPSL.

741 Figures in bold in the regional simulation columns indicate improvement compared to their 742 counterparts in global models.

\begin{tabular}{|c|c|c|c|c|c|c|c|c|c|c|c|c|}
\hline \multirow{2}{*}{\multicolumn{2}{|c|}{ Sta. }} & \multirow{2}{*}{$\begin{array}{l}\mathbf{E L} \\
(\mathbf{m})\end{array}$} & \multicolumn{4}{|c|}{$\triangle \mathbf{E L}(\mathbf{m})$} & \multicolumn{2}{|c|}{$\triangle \mathbf{T}\left({ }^{\circ} \mathrm{C}\right)$} & \multicolumn{2}{|c|}{$\triangle \mathbf{T}-\operatorname{cor}\left({ }^{\circ} \mathrm{C}\right)$} & \multicolumn{2}{|c|}{$\triangle \operatorname{Pr}(\%)$} \\
\hline & & & $\mathrm{BCCF}$ & 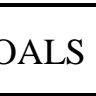 & IPSL & LMDZ & $\begin{array}{r}\text { GCM } \\
\text {-ave } \\
\end{array}$ & $\begin{array}{r}\mathrm{RCM} \\
\text {-ave } \\
\end{array}$ & $\begin{array}{r}\text { GCM } \\
\text {-ave }\end{array}$ & $\begin{array}{r}\mathrm{RCM} \\
\text {-ave }\end{array}$ & $\begin{array}{r}\text { GCM } \\
\text {-ave }\end{array}$ & $\begin{array}{r}\mathrm{RCM} \\
\text {-ave } \\
\end{array}$ \\
\hline$\overline{1}$ & Harbin & 142 & 129 & 245 & 139 & 63 & -2.83 & \begin{tabular}{|c|}
-0.37 \\
\end{tabular} & -1.72 & 0.01 & 35 & -7 \\
\hline 2 & Shenyang & 49 & 187 & 247 & 86 & 48 & -2.29 & -0.47 & -1.17 & -0.18 & 7 & -21 \\
\hline 3 & Chifeng & 568 & 65 & 199 & 154 & -30 & -2.73 & 0.18 & -1.82 & 0.08 & 68 & 2 \\
\hline 4 & Hohhot & 1063 & 319 & 30 & 289 & 265 & -2.29 & -1.69 & -0.90 & -0.39 & 9 & -38 \\
\hline 5 & Beijing & 31 & 596 & 811 & 562 & 328 & -5.28 & -2.40 & -1.01 & -0.92 & 23 & 10 \\
\hline 6 & Jinan & 170 & -127 & 107 & -24 & 10 & -2.52 & -0.48 & -2.61 & -0.42 & -7 & -18 \\
\hline 7 & Nanjin & I & 46 & 102 & 50 & 92 & -1.10 & -0.25 & -0.67 & 0.30 & -2 & -1 \\
\hline 8 & Hank & 23 & 103 & 263 & 127 & 39 & -1.44 & 1.00 & -0.37 & 1.24 & -23 & -38 \\
\hline 9 & Fuzhou & 84 & 247 & 186 & 173 & 439 & 0.27 & -0.98 & 1.59 & 1.66 & -10 & -5 \\
\hline 10 & Nanchang & 47 & 166 & 239 & 249 & -4 & -1.64 & 0.50 & -0.22 & 0.48 & -36 & -31 \\
\hline 11 & Chan & 68 & 140 & 316 & 203 & 41 & -1.28 & 0.93 & 0.15 & 1.18 & -40 & -36 \\
\hline 12 & Guar & 41 & 11 & 196 & 155 & 13 & -0.91 & -0.03 & 0.10 & 0.05 & -36 & -34 \\
\hline 13 & Nanning & 122 & 15 & & 192 & 71 & -0.80 & -0.57 & 0.51 & -0.15 & -38 & -9 \\
\hline 14 & Guizh & 1224 & -17 & -251 & -158 & 215 & 1.47 & -0.71 & 0.21 & 0.58 & -19 & -22 \\
\hline 15 & Chon & 351 & 20 & 767 & 383 & 66 & -3.08 & 1.32 & -0.15 & 1.72 & -25 & -64 \\
\hline 16 & Che & 506 & 1492 & & -6 & 27 & -5.40 & 0.87 & 0.88 & 1.04 & 18 & -65 \\
\hline 17 & $\mathrm{Xi}$ & 15 & 79 & & 77 & 652 & -0.83 & -1.67 & 3.73 & 2.24 & 10 & -39 \\
\hline 18 & $\mathrm{Ku}$ & 18 & 90 & & 1 & 25 & 0.59 & -1.02 & -0.36 & -0.27 & -8 & -25 \\
\hline 19 & Lha & 3649 & 120 & & 1026 & 854 & -5.35 & -3.89 & -0.12 & 1.23 & 86 & -65 \\
\hline 20 & Xi'ar & 397 & & & 57 & 685 & -4.17 & -2.33 & -0.26 & 1.17 & 52 & 26 \\
\hline 21 & Lanzh & 1517 & & & 56 & 781 & -3.85 & -1.32 & 1.06 & 1.36 & 151 & 49 \\
\hline 22 & Yincl & 1111 & 270 & 4 & 544 & 308 & -3.48 & -1.51 & -0.73 & 0.33 & 77 & 15 \\
\hline 23 & Xining & 2295 & 952 & 419 & 518 & 560 & -3.54 & -1.89 & 0.55 & 1.47 & 58 & -7 \\
\hline 24 & Yushu & 3681 & 915 & 533 & 1127 & 865 & -3.08 & -2.07 & 2.50 & 3.12 & 55 & -43 \\
\hline 25 & Urumq & 935 & 245 & 337 & -219 & -214 & 1.88 & 4.17 & 2.67 & 2.89 & 2 & -35 \\
\hline & solute-Ave & 862.3 & 408 & 412 & 340 & 272 & 2.53 & 1.13 & 1.09 & 0.98 & 35.8 & 28.2 \\
\hline
\end{tabular}



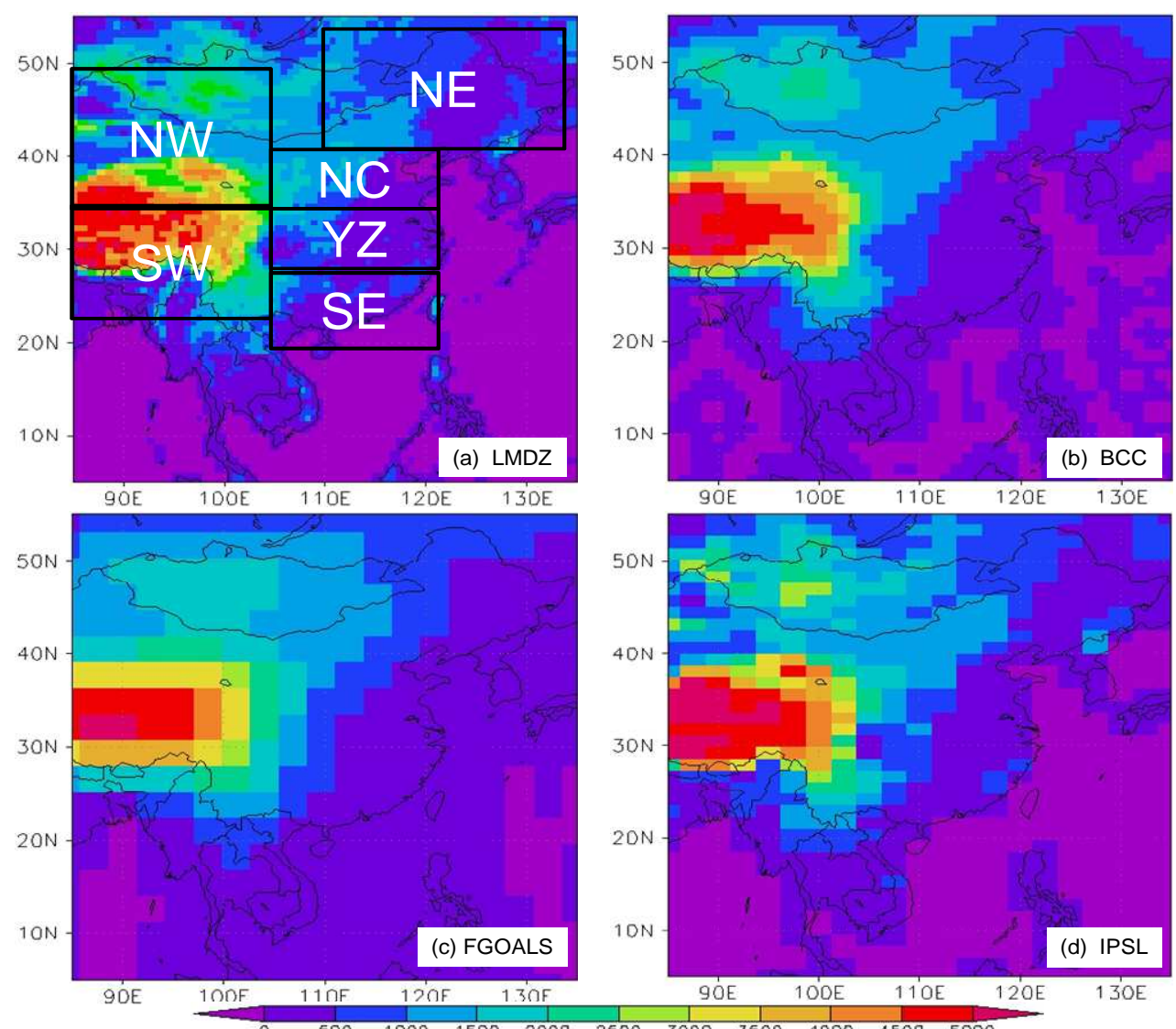

Fig.1. Grid (in the form of mosaic) and surface orography (bottom color shading in $\mathrm{m}$ ) of models (a) LMDZ, (b) BCC, (c) FGOALS, (d) IPSL in East Asia 

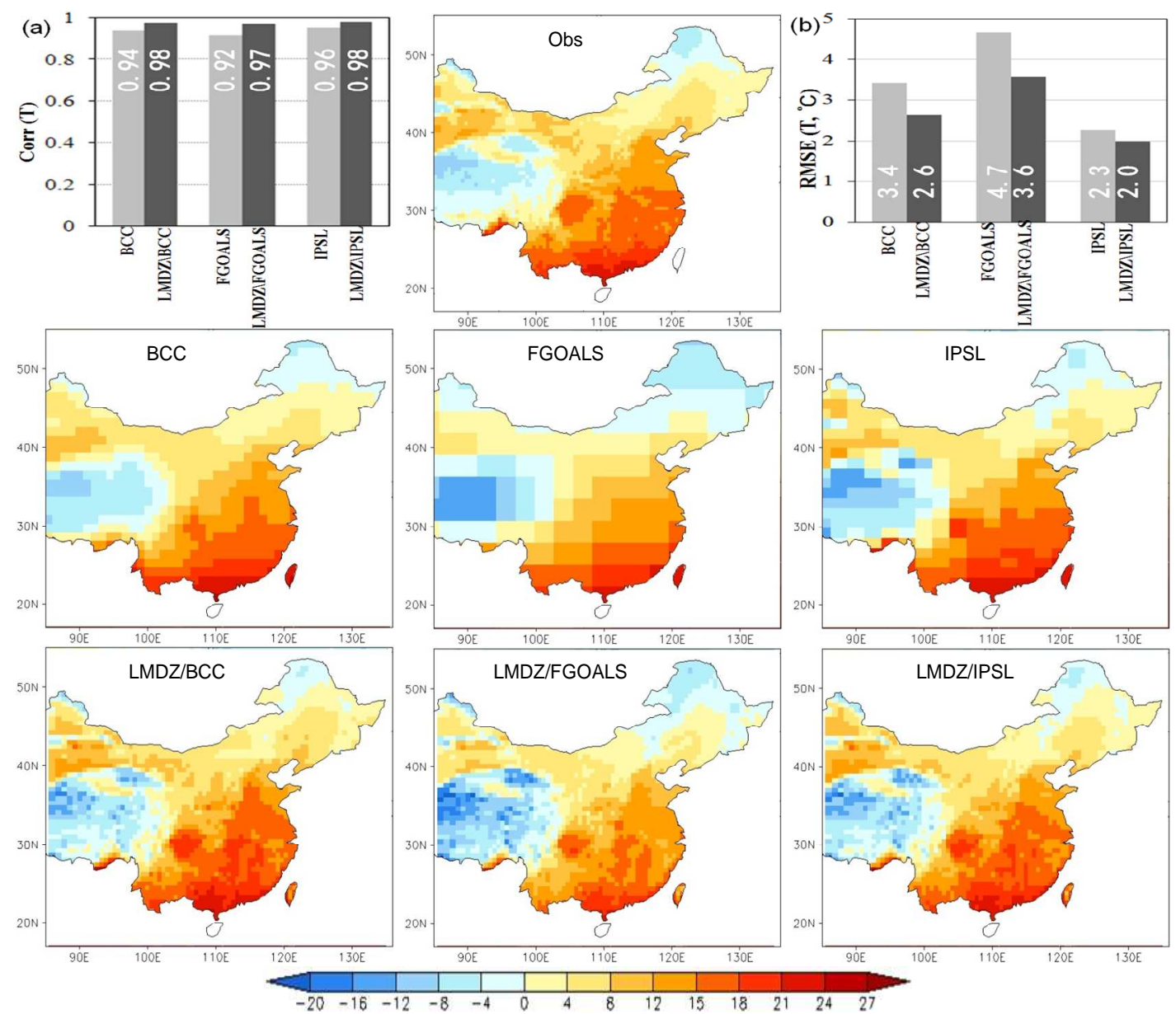

Fig. 2 Distribution of annual-mean temperature $\left({ }^{\circ} \mathrm{C}\right)$ during 1961-2005 from observation (top), GCMs (middle row, BCC, FGOALS, IPSL) and downscaling simulations (bottom row, LMDZ/BCC, LMDZ/FGOALS, LMDZ/IPSL) over China. Spatial-pattern correlation coefficients and root-mean-square error (RMSE) between the observed and simulated fields are given in panels $a$ and $b$. 

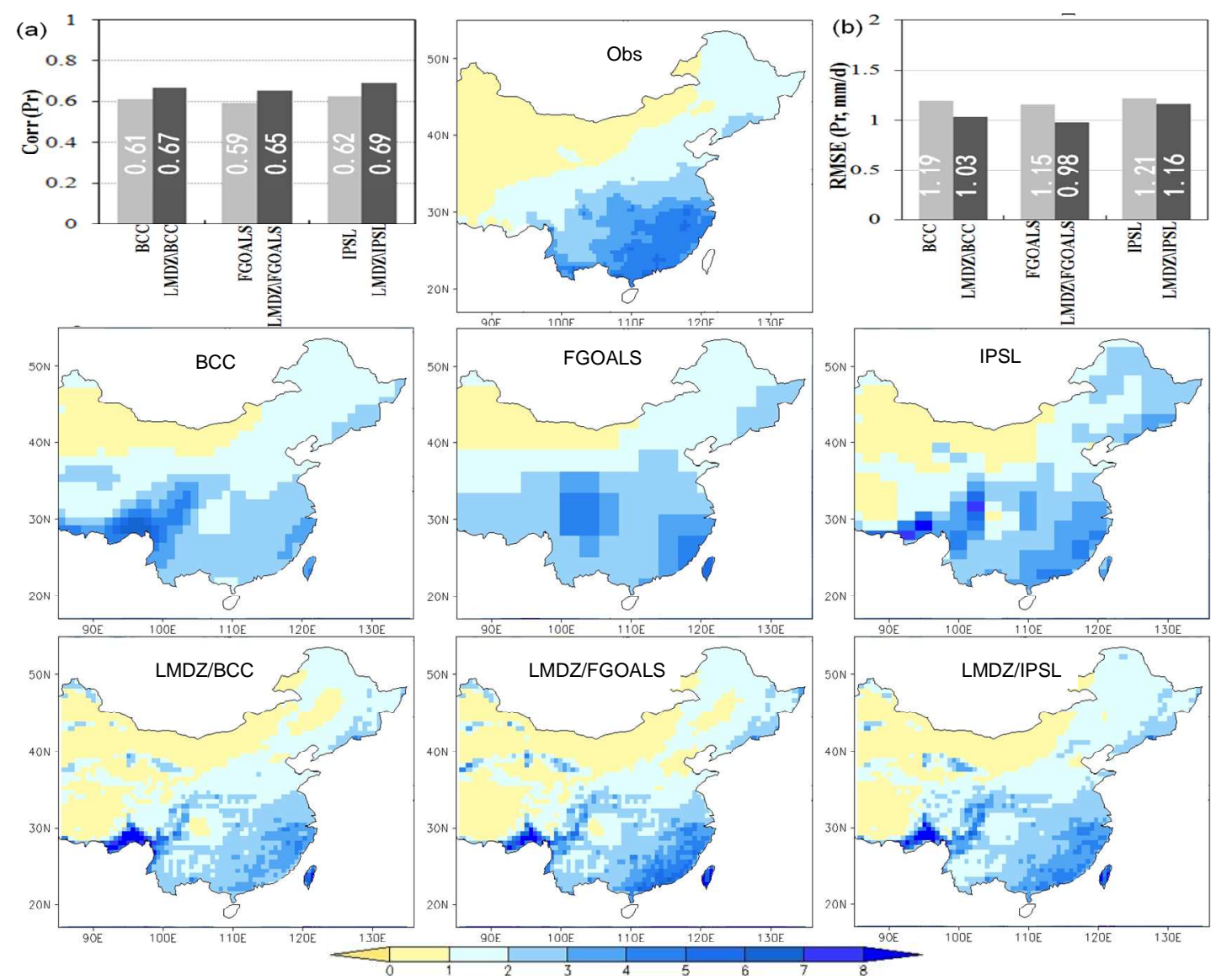

Fig. 3 Same as in Fig. 2, but for precipitation (mm/day). 

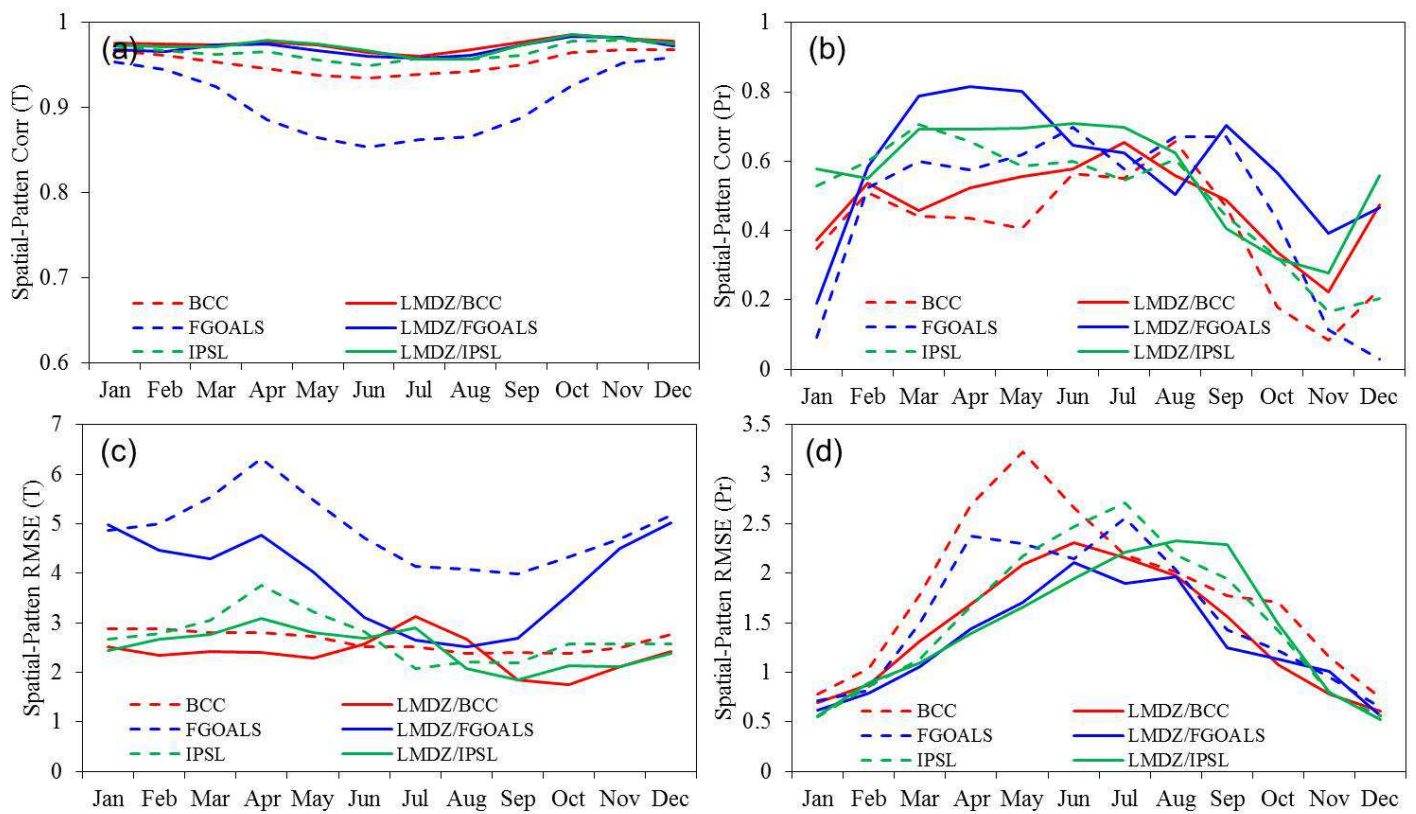

Fig.4 Seasonal evolution of Spatial-pattern

$(a, b)$ correlation coefficients and (c, d) root-mean-square error (RMSE) between the observed fields and simulated ones for (a, c) temperature and $(b, d)$ precipitation. 


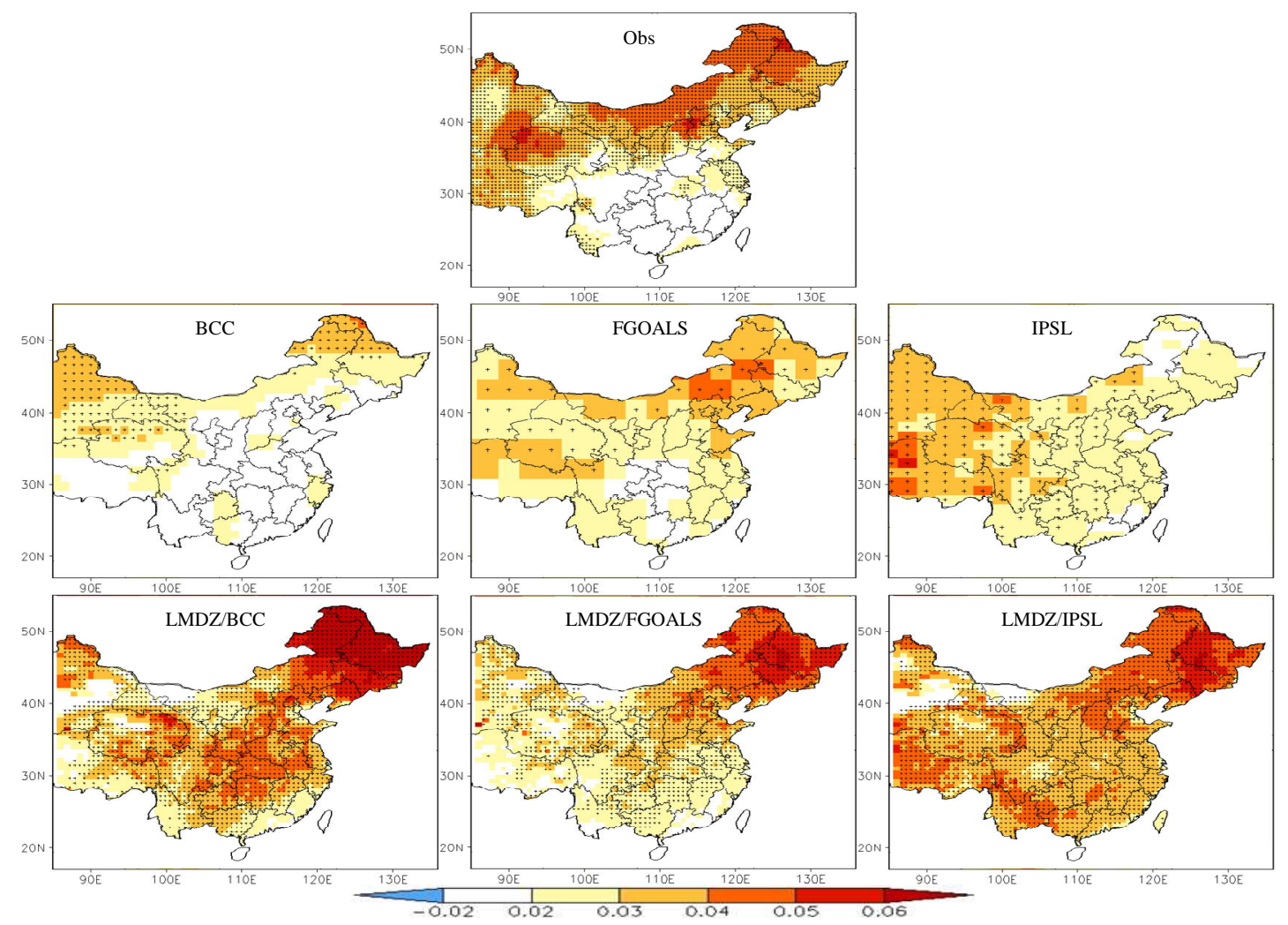

768 Fig. 5 Long-term trend of annual-mean temperature (units: ${ }^{\circ} \mathrm{C} \cdot(\mathrm{a}){ }^{-1}$, stippling indicates areas

769 where the trend is statistically significant at the $95 \%$ confidence level). The layout of panels is the

770 same as in Fig. 2: observation on the top, GCMs in the middle and downscaling simulations on the 771 bottom. 


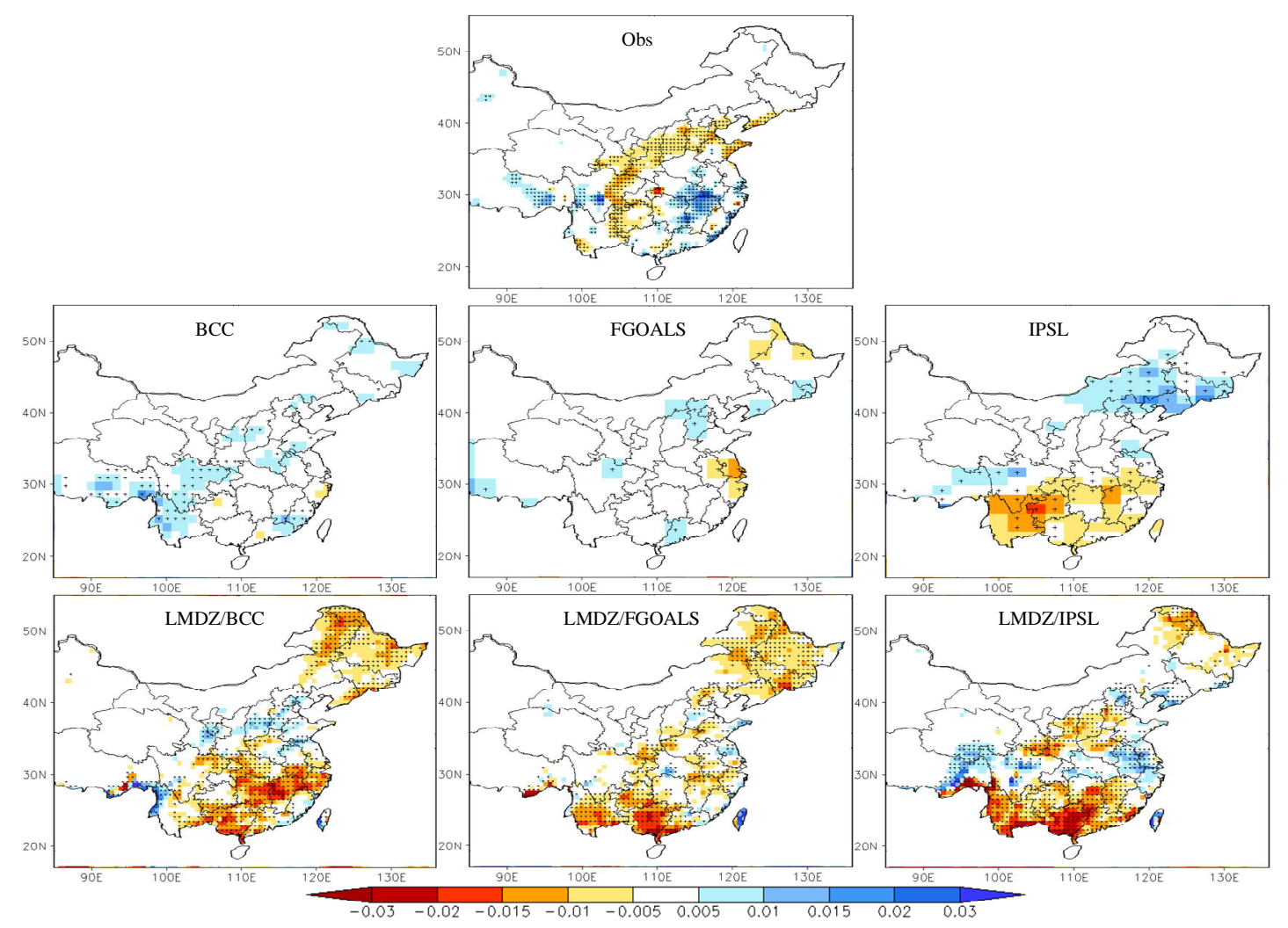

774 Fig. 6 Same as in Fig. 5, but for long-term trend of annual precipitation (units: $(\mathrm{mm} / \mathrm{d}) \cdot(\mathrm{a})^{-1}$, 775 stippling indicates areas where the trend is statistically significant at the $95 \%$ confidence level). 


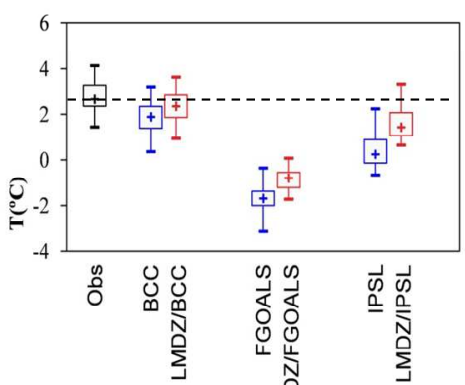

(NW) Data $\sum_{-}$

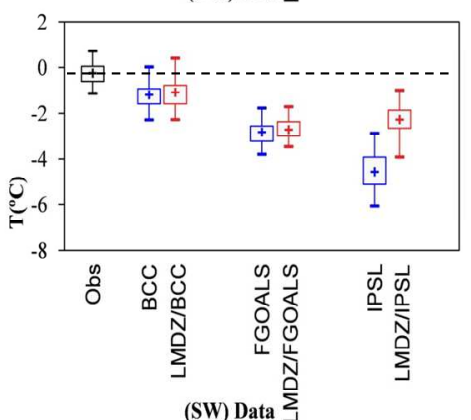

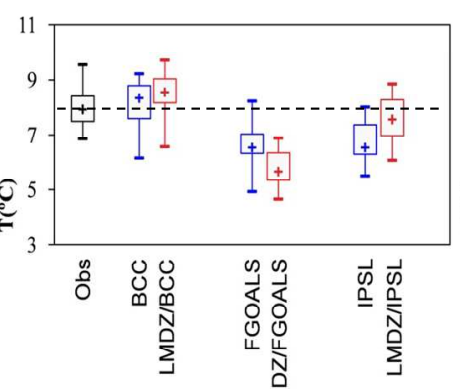

(NC) Data

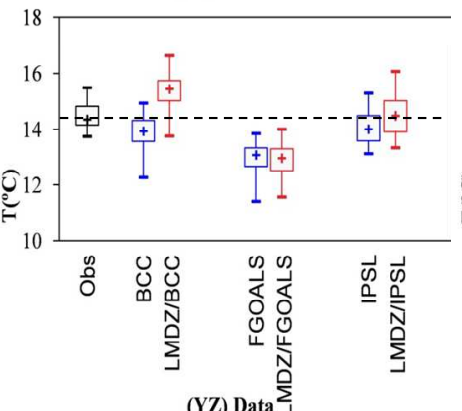

(YZ) Data $\sum$

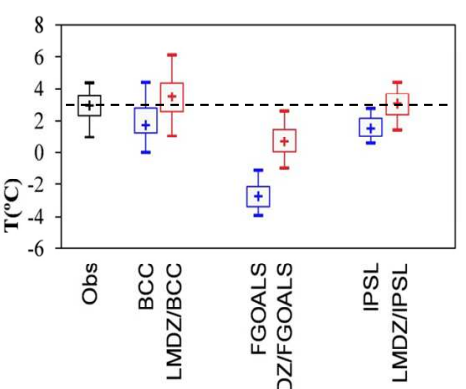

(NE) Data $\sum_{J}$

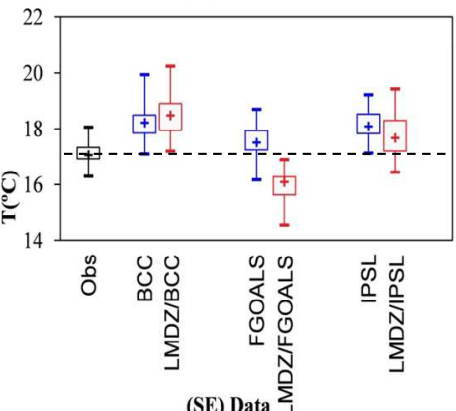

Fig. 7 Distribution of annual temperature during 1961-2005 for different data sets and different regions. These box and whisker plots show the median (“+”), inter-quartile range, maximum and minimum of temperatures respectively (unit: ${ }^{\circ} \mathrm{C}$ ). 

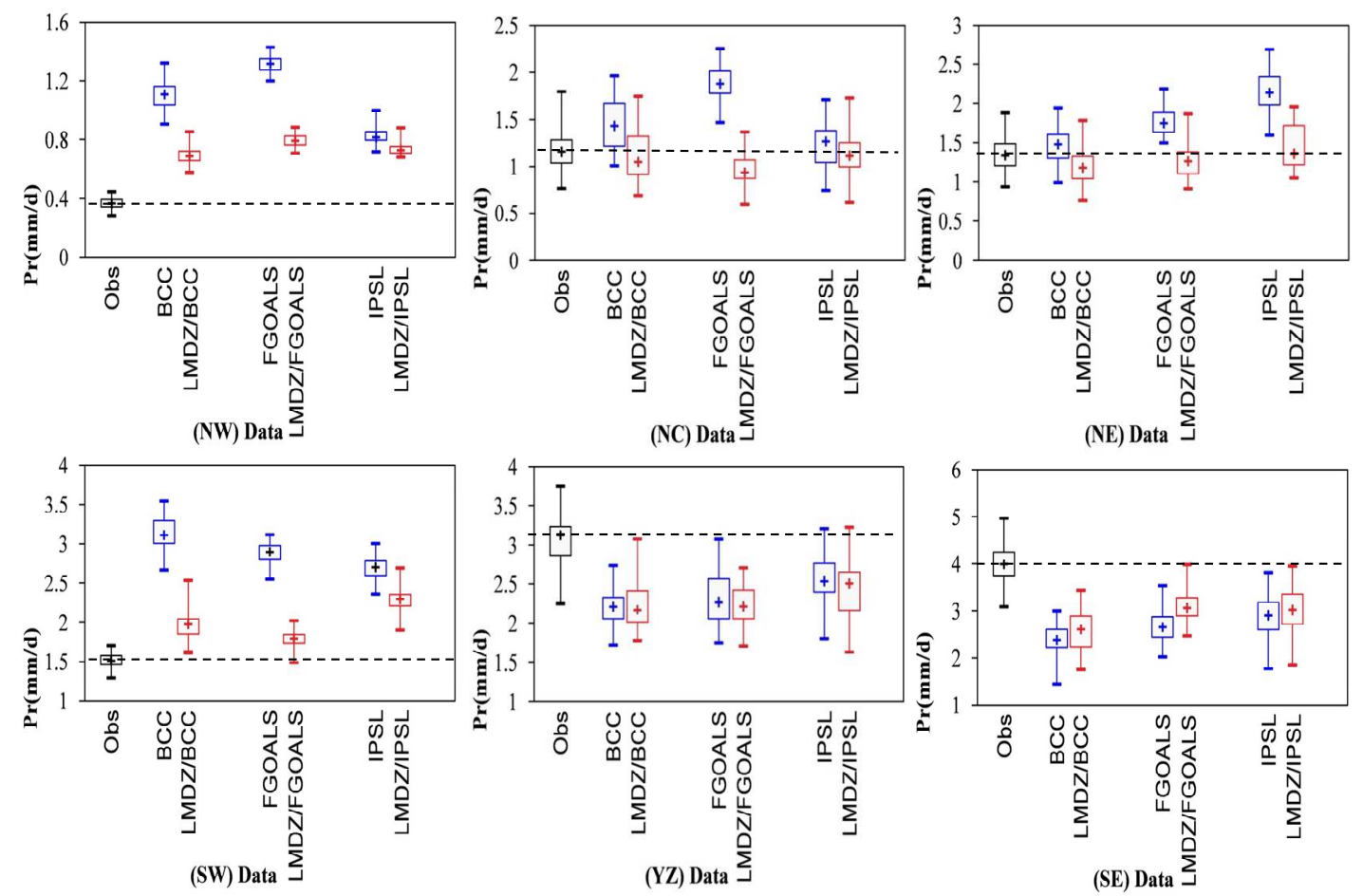

783

Fig. 8 Same as in Fig. 7, but for the annual precipitation (unit: mm/day). 

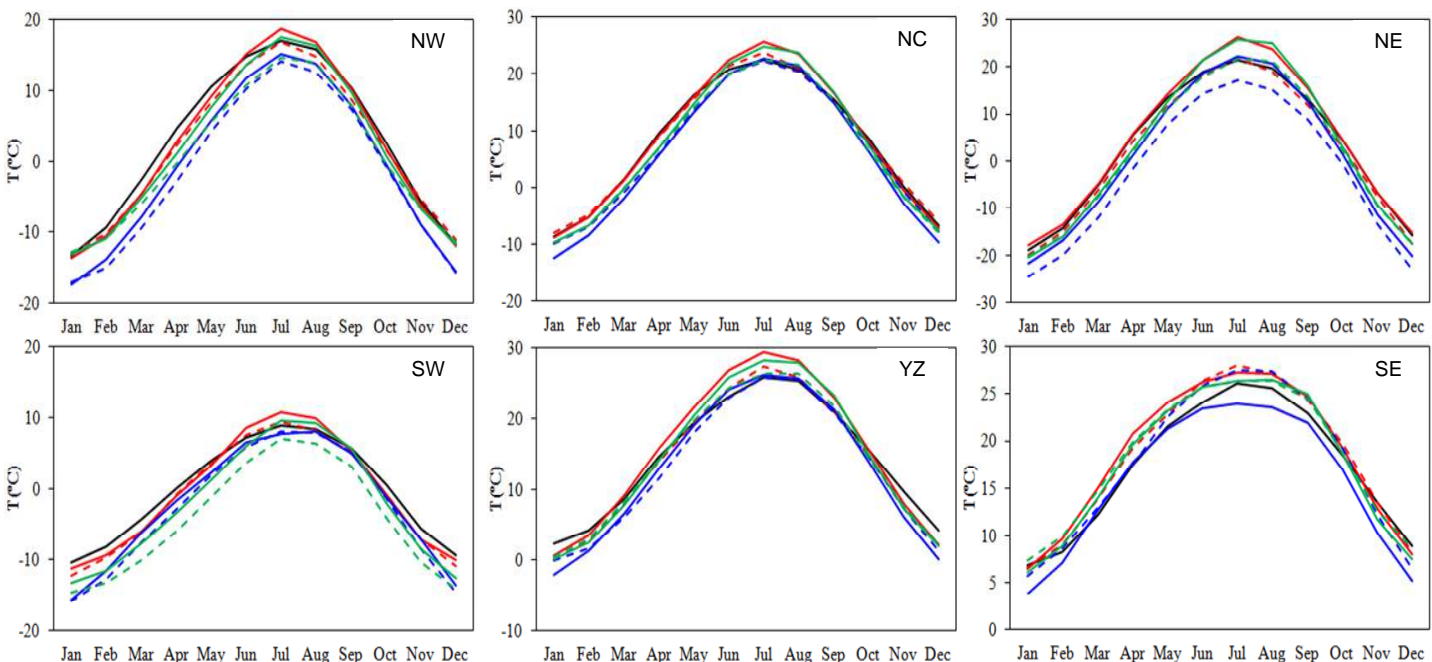

$$
---\mathrm{BCC}
$$
Obs

Fig. 9 Seasonal cycle of monthly-mean surface air temperature $\left({ }^{\circ} \mathrm{C}\right.$ ) during 1961-2005 for different datasets and different regions. 

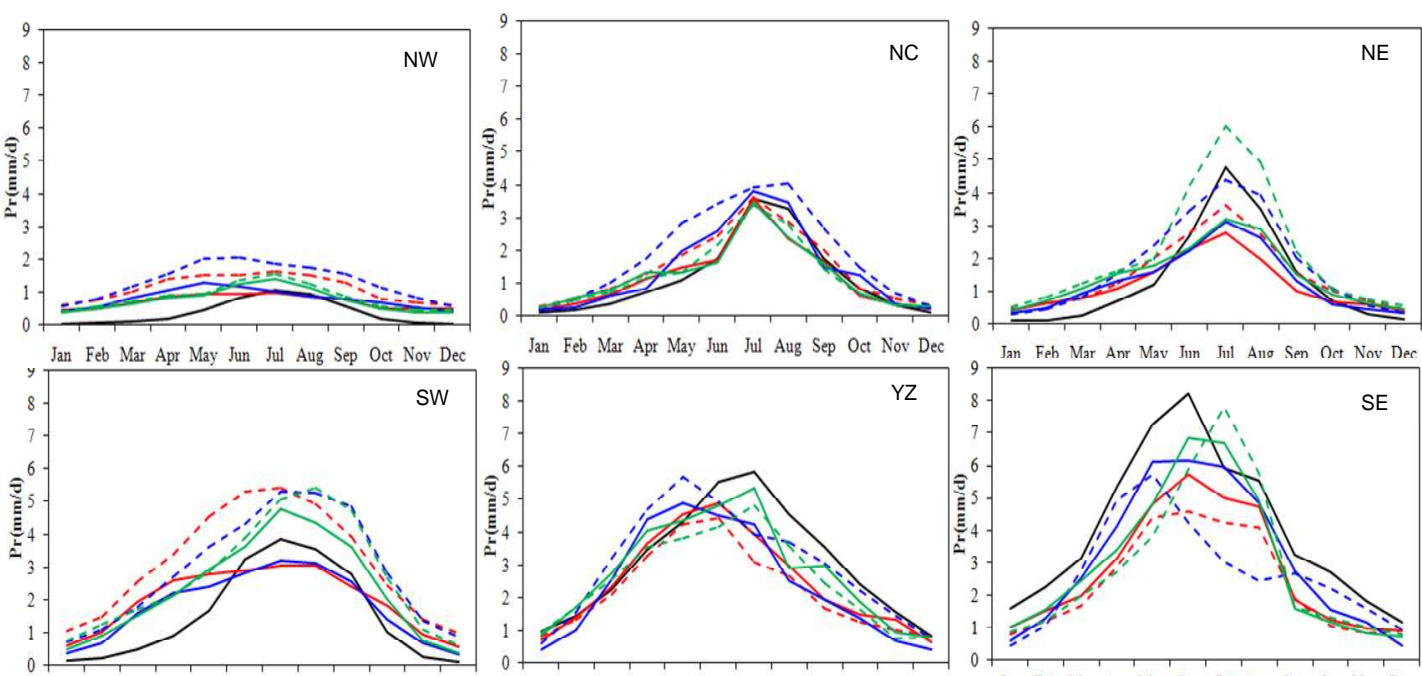

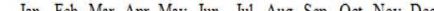
Jan Feb Mar Aor Mav Jun Jul Auc Seo Oct Nov D

Jan Feb Mar Apr May Jun Jul Aug Sep Oct Nov Dec - - - BCC ALS

-IPSL

Fig. 10. Same as in Fig. 9, but for precipitation (mm/day). 


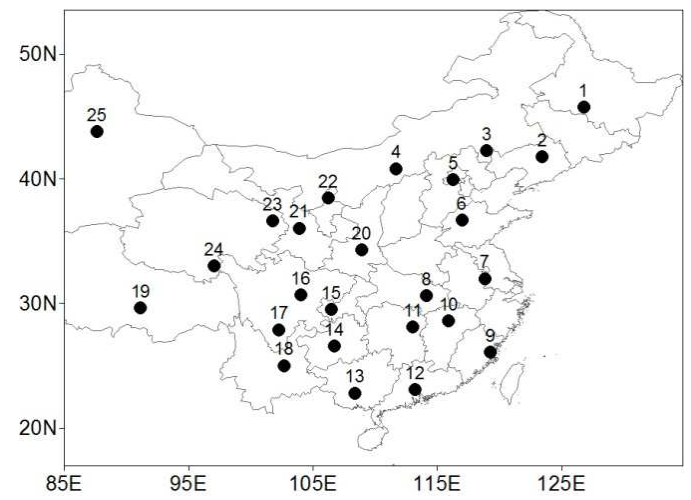

795

Fig. 11. Geographic positions of the 25 representative stations in China 

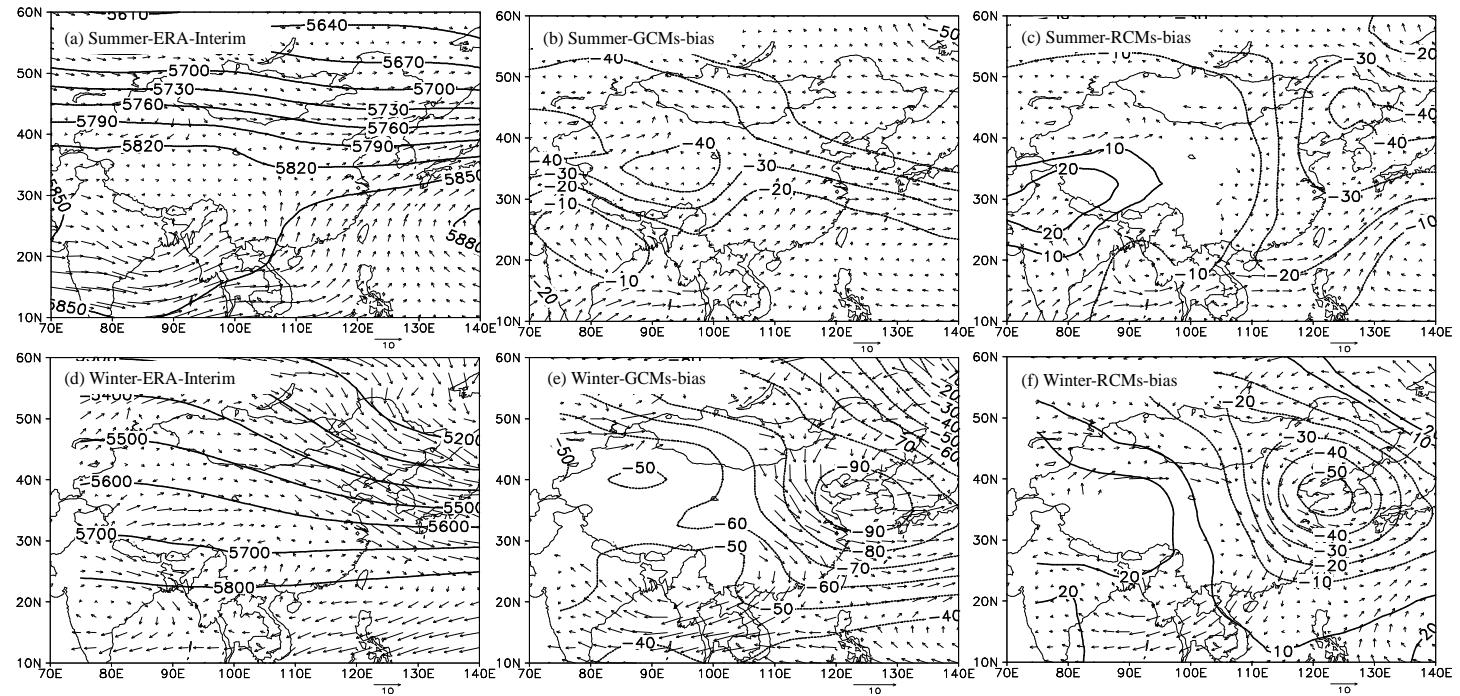

Fig. 12. Climatological mean of geopotential height at $500 \mathrm{hPa}$ (contours, unit: dagpm) and winds at $850 \mathrm{hPa}$ (vectors, unit: $\mathrm{m} / \mathrm{s}$ ) for (a,d) ERA-interim and biases in (b,e) GCMs-ave and (c,f) RCMs-ave ( $a, b, c$ for summer, $d, e, f$ for winter). 